\title{
الضغوط النفسية لدى ذوي صعوبات التعلم
}

Psychological stress among people with learning disabilities

\author{
إعlul \\ موضيد عبد الله حلمون الحسون \\ Moudhi Abdullah Hassoun Al-Hassoun \\ Qassim University - قسم التربية الخاصة مسارصعوبات التعلم - جامعة القصيم
}

Doi: 10.21608/jasht.2021.182629

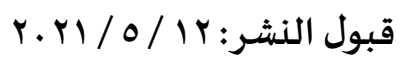

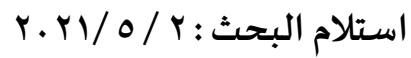

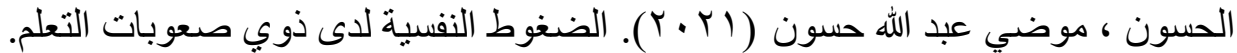

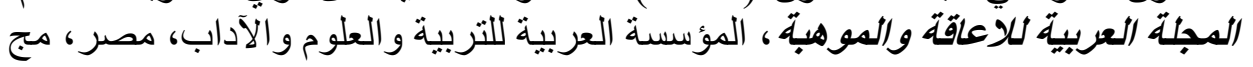

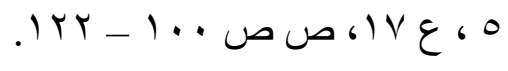


الضغوط النفسية لاى ذوي صعوبات التعلم

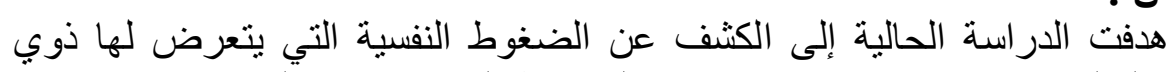

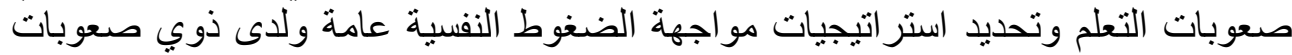

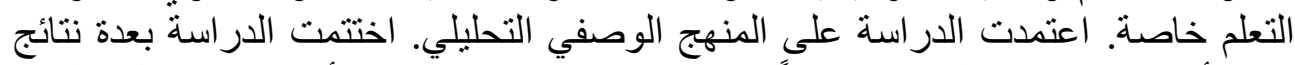

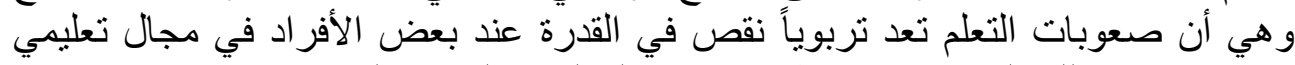

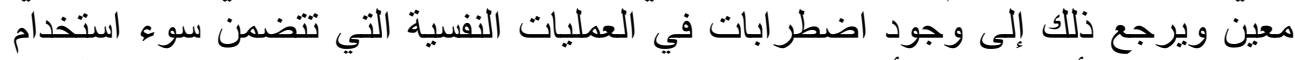

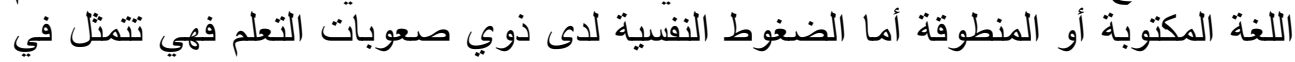

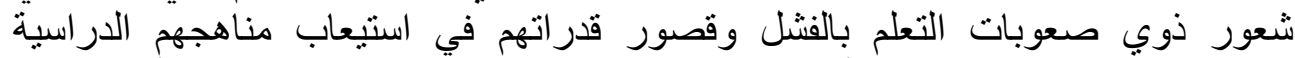

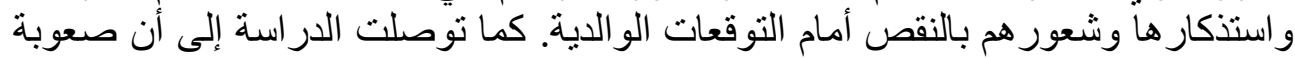

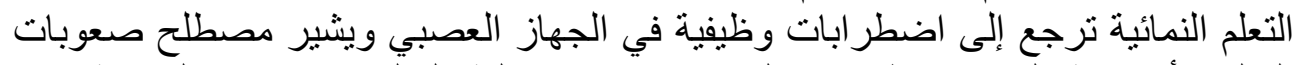

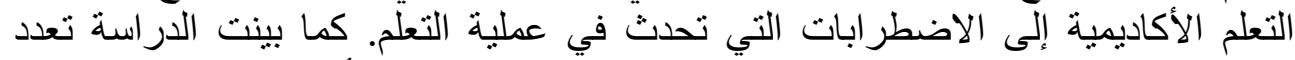

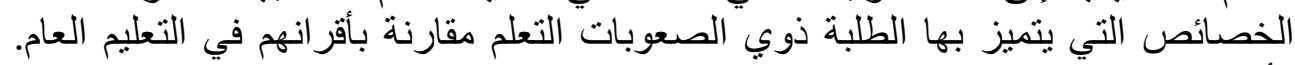

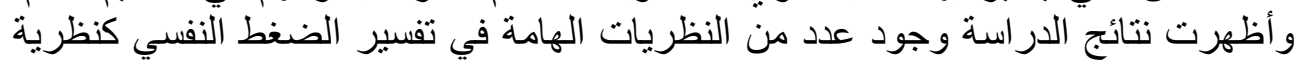

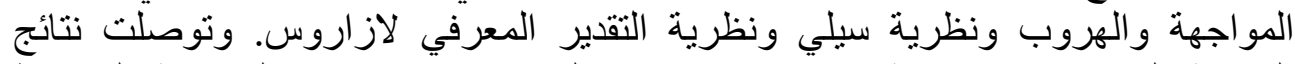

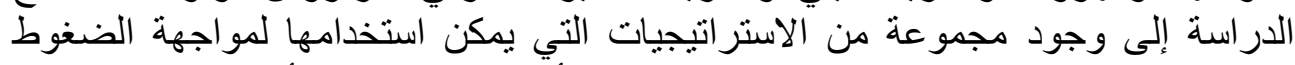

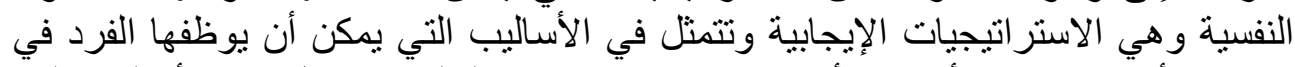

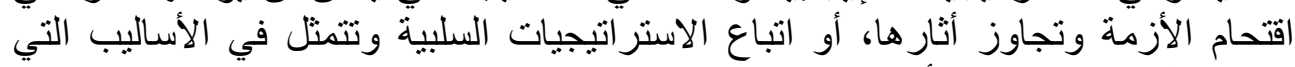

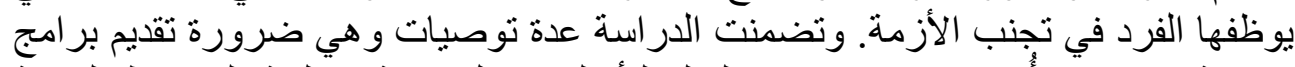

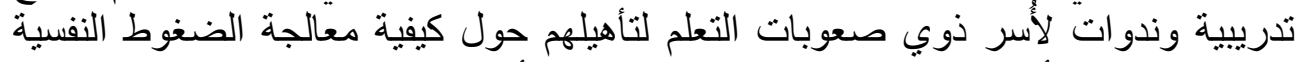

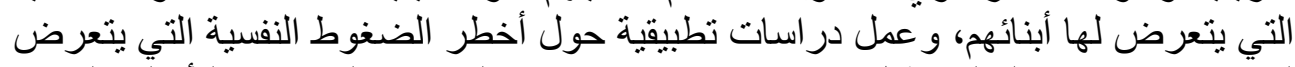

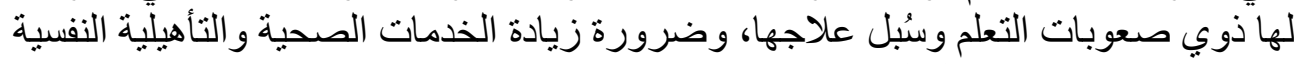

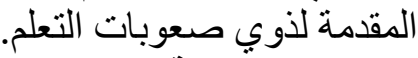

\section{Abstract}

The present study aimed to uncover the psychological pressures that people with learning disabilities are exposed to and to identify strategies for facing psychological pressures in general and for those with learning disabilities in particular. The study relied on the descriptive and analytical approach. The study concluded with several results, which is that learning disabilities are considered educational, 
as a lack of ability for some individuals in a particular educational field, and this is due to the presence of disturbances in psychological processes that include the misuse of written or spoken language. By failure and lack of their abilities to absorb and recall their curriculum, and their feeling of inferiority in front of parental expectations. The study also found that developmental learning disabilities is due to functional disorders in the nervous system, and the term academic learning disabilities refers to disorders that occur in the learning process. The study also revealed the multiplicity of characteristics that characterize students with learning disabilities compared to their peers in general education. The results of the study revealed the existence of a number of important theories in the interpretation of psychological stress, such as the theory of confrontation and escape, the theory of Sealy and the theory of cognitive appreciation of Lazarus. The results of the study concluded that there is a set of strategies that can be used to confront psychological pressures, which are the positive strategies and are represented in the methods that the individual can employ in storming the crisis and overcoming its effects, or following the negative strategies represented in the methods that the individual employs in avoiding the crisis. The study included several recommendations, namely the necessity to provide training programs and seminars for families with learning disabilities to qualify them on how to deal with the psychological pressures that their children are exposed to, and to conduct applied studies on the most dangerous psychological pressures that people with learning disabilities are exposed to and ways to treat them, and the need to increase the health and psychological rehabilitation services provided to those with

Learning disabilities.

Keywords: Psychological stress, students, education, learning disabilities. 
لقد تعددت القضايا و المشكلات النفسية والتربوية بمجال علم النفس، و وعلى رأسها

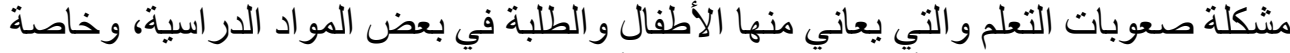

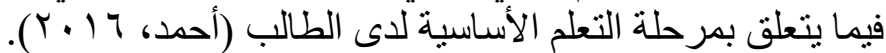

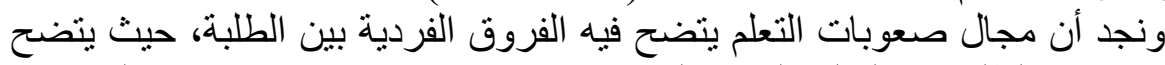

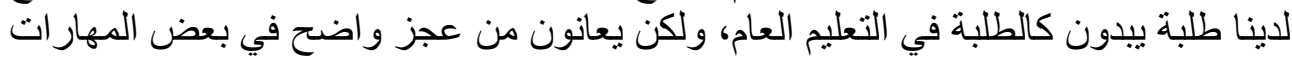

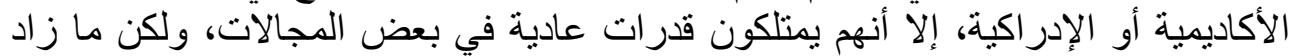

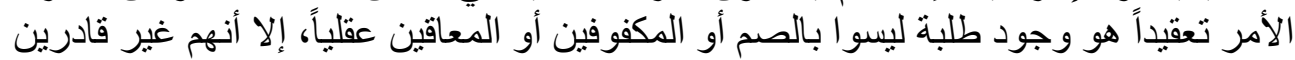

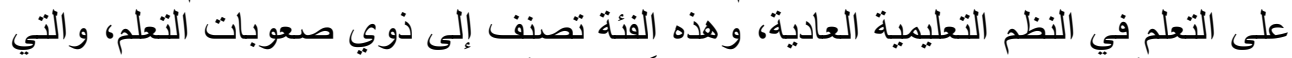

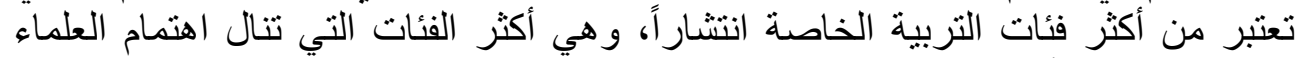

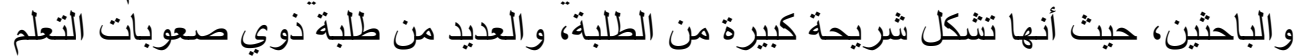

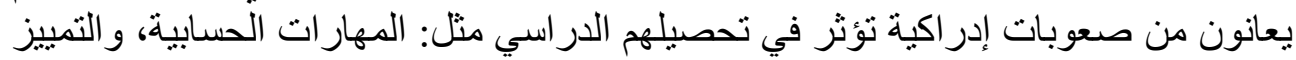

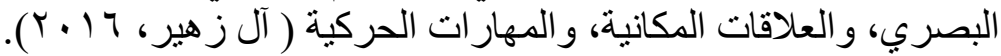

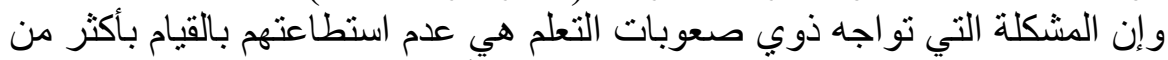

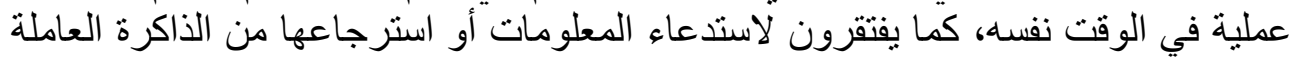

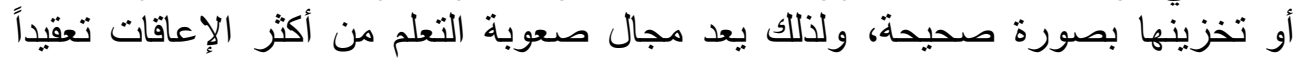

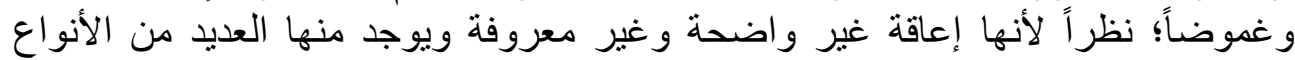

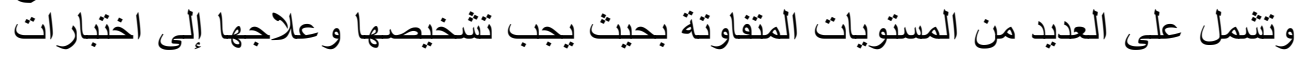

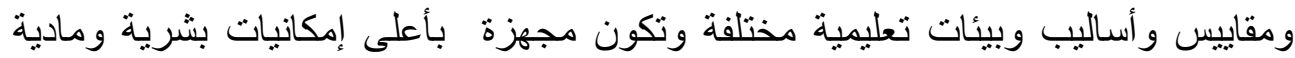
متخصصة لخدمة ذلك النوع من الإعاقة ويكون ذللك في نطاق المدرسة التقليدية ( العبري،

( $($. 17

وفي ظل ذللك يتعرض الطلبة ذوي صعوبات التعلم إلى ضغوطات ومشكلات

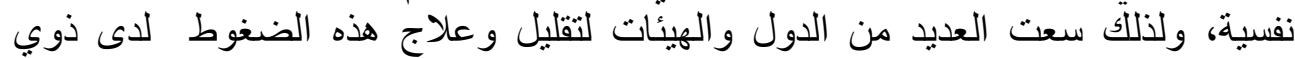

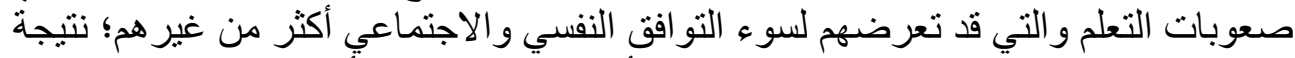

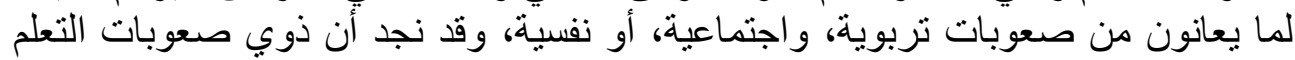

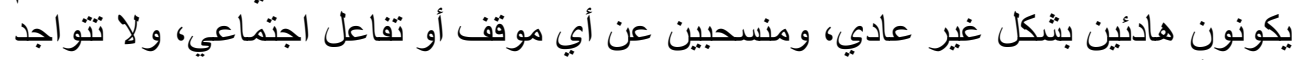

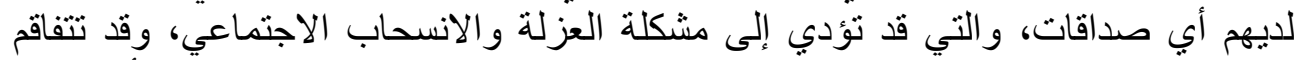

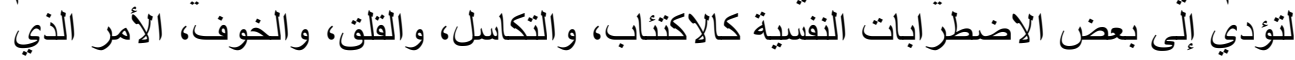

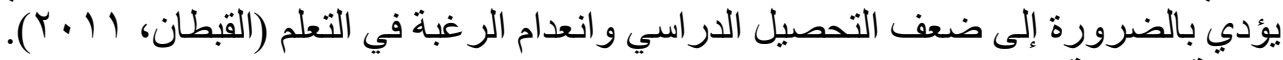
مشكنة الار باسة

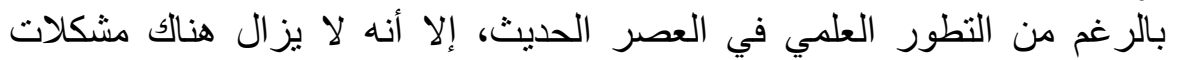

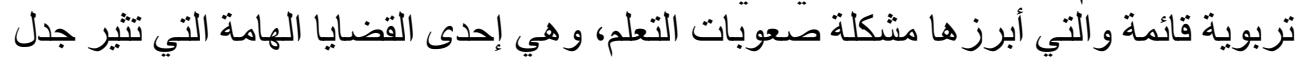


التربوبين و علماء النفس، و هي صعوبات التعلم، والتي تظهر منذ مرحلة الطفولة المبكرة، وتؤثر بدور ها في التحصيل الدراسي كما تؤثر على المر احل الدر اسية المستقبلية للطلبة، وقداء

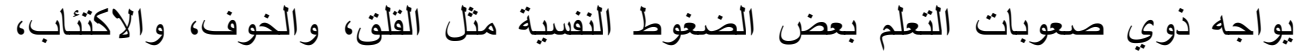
والعزلة، ولذللك سلطت الدراسة الضوء على على الضغوط النفسية لدى ذوي صعوبات التعلم، ومن هنا يمكننا صياغة مشكلة الدراسة في عدة تساؤلات الت وهي:

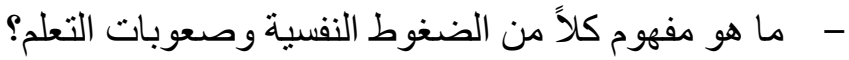

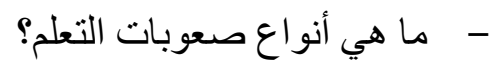

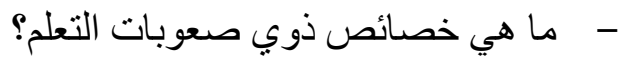
- ما هي العو امل المسببة لصعوبات التعلم؟ - ما هي مظاهر الضغوط النفسية؟ - ما هي النظريات المفسرة للضغوط مهر النفسية؟ - ما هي الضغوط النفسية التي تواجه ذوي صعوبات التعلم؟ - ما هي أساليب مواجهة الضغوط النفسية؟ أهمية الدراسة أهي

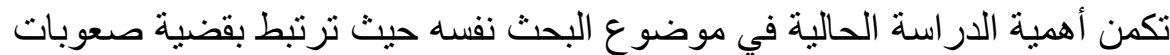

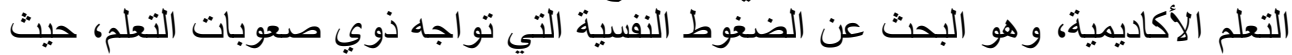
تفيد هذه الدر اسة بالاهتمام بفئة محددة من ذوي صعوبات التعلم بتوضيح العلاقة القوية بين الضغط النفسي وصدوهيات التعلم. ومن الناحية العملية يمكن من خلال نتائج الدراسة وتوصياتها أن تساعد الجهات المختصة في تقديم برنامج تدريبي يهدف لمعالجة الضغوط النفسية لذوي صعوبات التعلم،

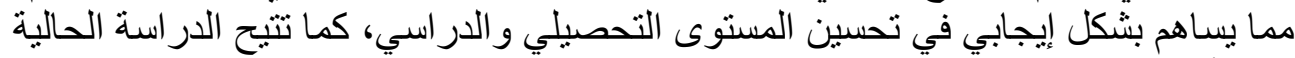

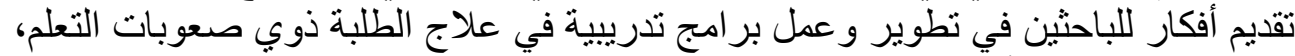
كما تفيد الدراسة الأخصائيين والتربويين في مجال تحسين الحالة النفسية و التكيف البيئي والاجتماعي لذوي صعوبات التعلم و العمل على مساعدتهم بالاندماج مع أقرانهم في التعليم

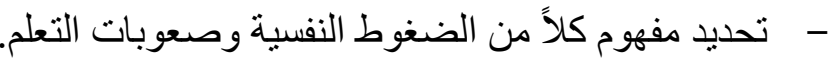

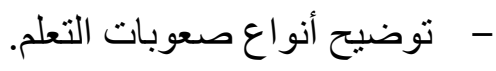

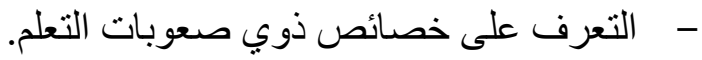
- - التعرف على العو امل المسببة لصعوفيات التعلم. 


$$
\begin{aligned}
& \text { - - تحديد مظاهر الضغوط النفسية. } \\
& \text { - - توضيح النظريات المفسرة للضغوط النفسية. }
\end{aligned}
$$

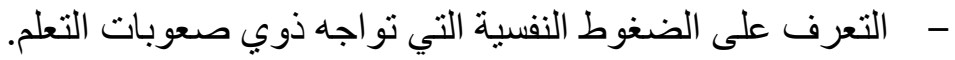

$$
\begin{aligned}
& \text { - التعرف على أساليب مواجهة الضغوط النفية. } \\
& \text { منهج الدراسة }
\end{aligned}
$$

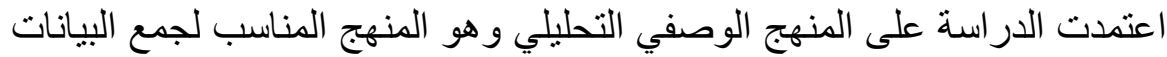

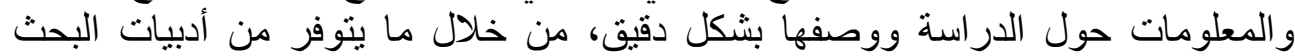

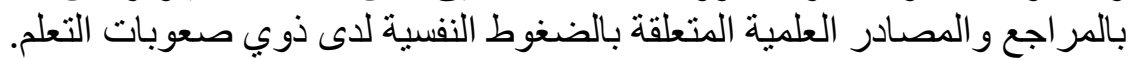

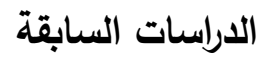

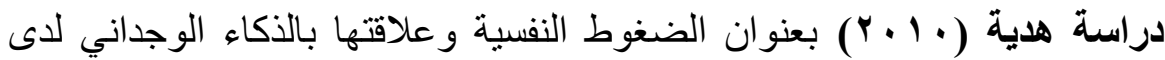

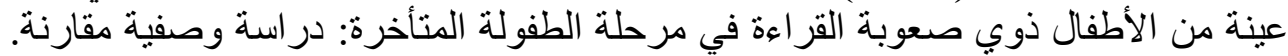

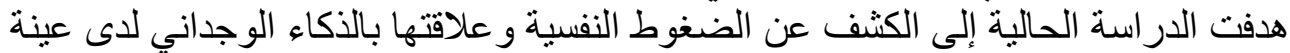

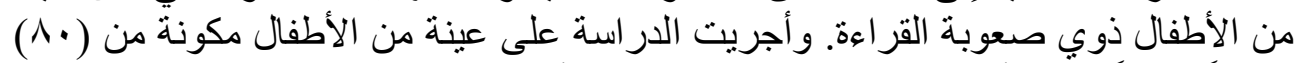

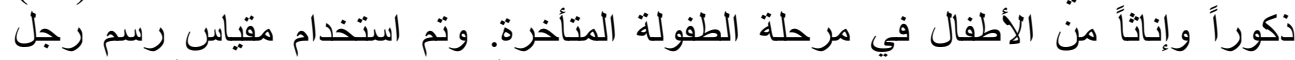

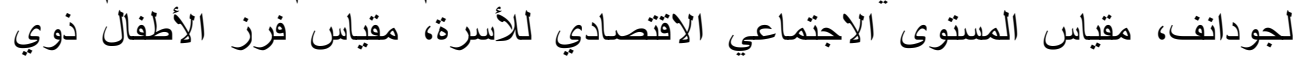

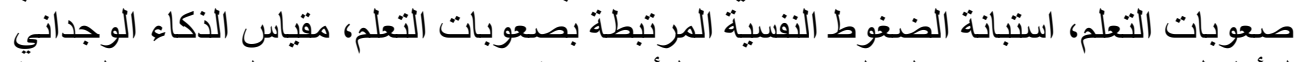

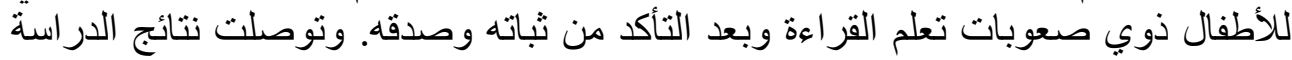
- وجود علاقة ارتباطية موجبة دالة إحصائياً بين الضغوط النفسية و الوعي بالذات وكانت

$$
\text { دالة عند مستوى (1 ( . , •). }
$$

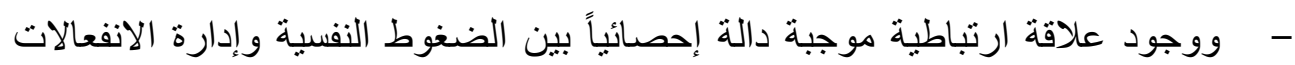

$$
\text { وكانت دالة عند مسنوى (0. • , •). }
$$

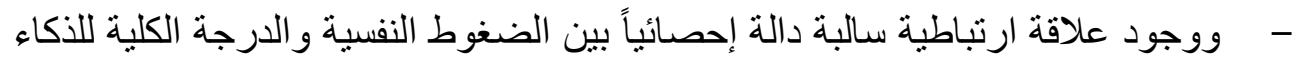

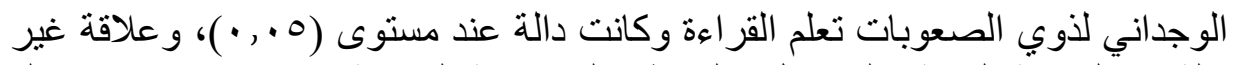

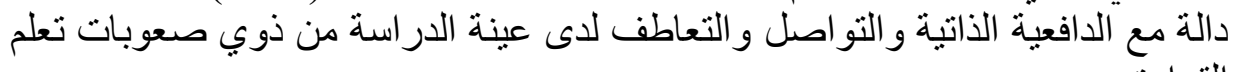

$$
\text { القراءة. }
$$

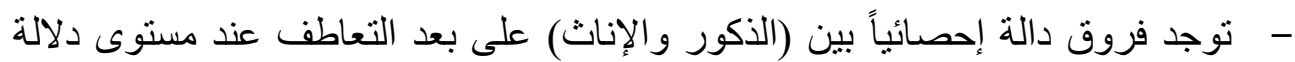

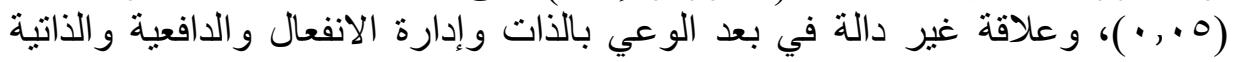

$$
\text { و التو اصل و الدرجة الكلية للذكاء الوجداني. }
$$

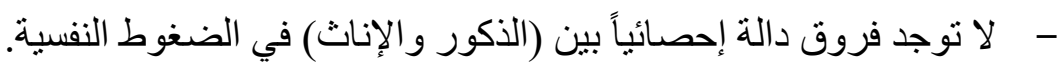


- - توجد فروق دالة إحصائياً بين (منخفضي ومرتفعي) المستوى الاجتماعي الاقتصادي في

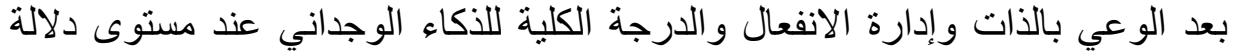

(0 ، , • )، و لا توجد هذه الفروق في أبعاد الدافعية الذاتية و التو اصل و التعاطف.

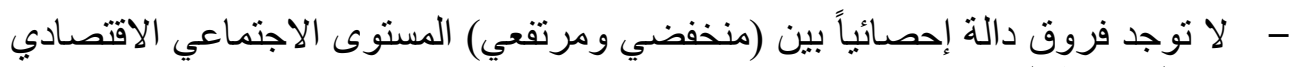
في الضغوط النفسية.

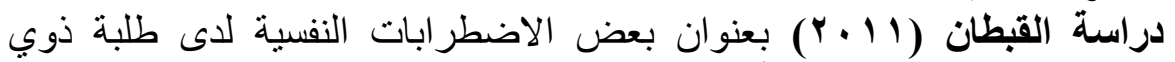

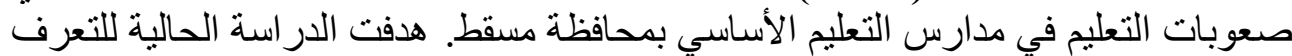

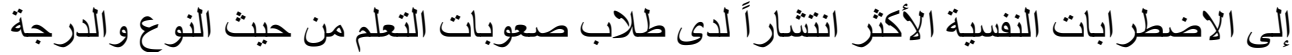

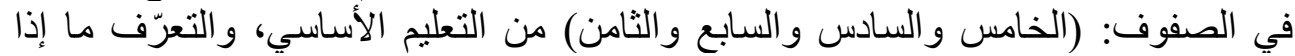
كانت هناك فروق ذات دلالة إحصائية في حدة الاضطر ابات النفسية لمستوى القلق و الاكتئاب

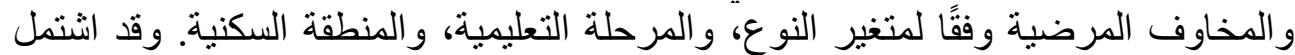
مجتمع الدراسة على جميع طلاب وطالبات ذوي صعوبات التعلم من مدارس الحلقة الثانية بو لايات محافظة مسقط، والبالغ عددهم سه إ طالب وطالبة من طلبة ذوي صعوبات التعلم،

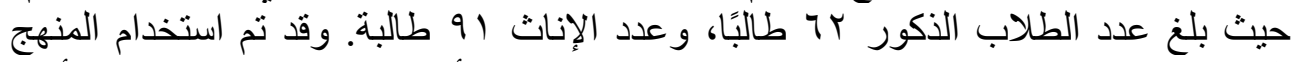
الوصفي في هذه الدراسة. وتوصلت نتائج الدراسة إلى أن الاضطرابات النفسية الأكثر انتشاراً لدى الطلبة من ذوي صعوبات التعلم في الصفوف (الخامس، و السادس، و السابع،

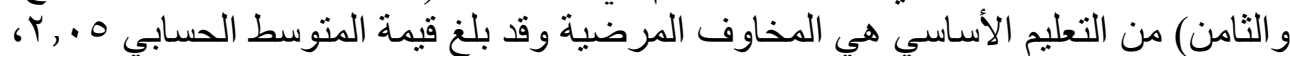

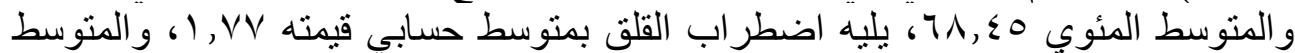

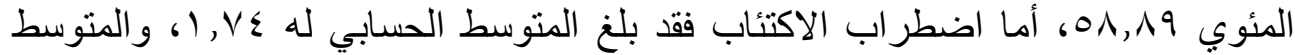

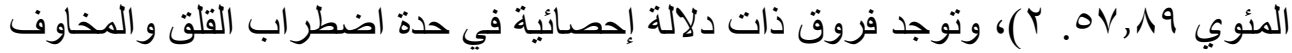
المرضبة وفق متغير النوع.

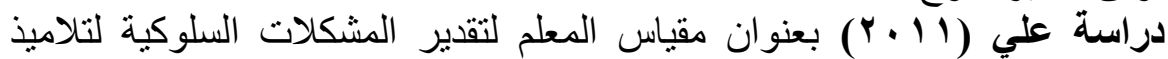

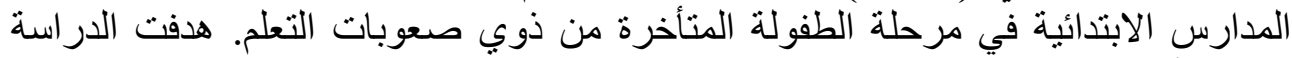

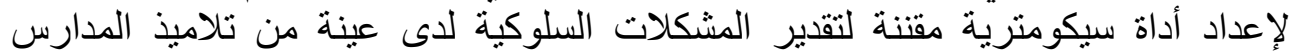
الابتدائية في مرحلة الطفولة المتأخرة من ذوي صعوبات التعلم، و التأكد من كفاءة تلك ملك الأداة سيكومترياً من خلال القيام بتقنينها، وإيراز الحاجة إلى وجلى ودود مقياس مقنن لتقدير المشكلات

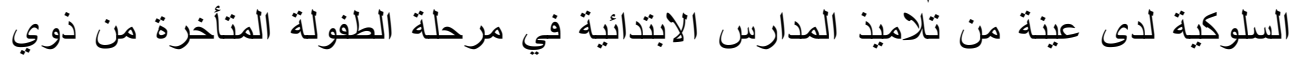
صعوبات التعلم الخاصة و أن معظم المقاييس التي صممت ومنها لتها المقياس التي قامت الباحثة بتعديله وتقنينه في هذه الدر اسة اعتمدت على بيانات معيارية من جمهور الطناب المر الهي اهقين

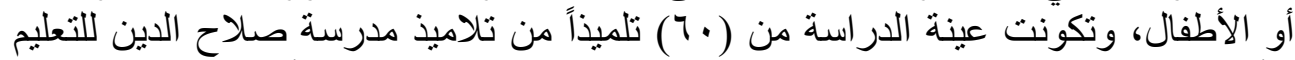

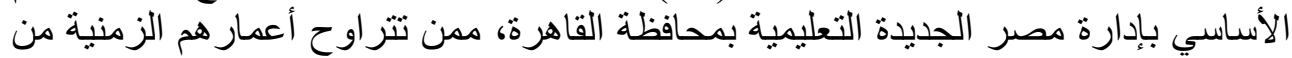
( • ( : Y ( ) سنة، وقد استخدمت الباحثة مقياس تقدير الخصائص السلوكية لذوي صعوبات 


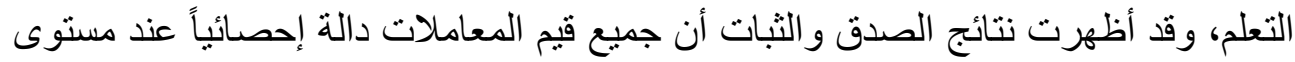

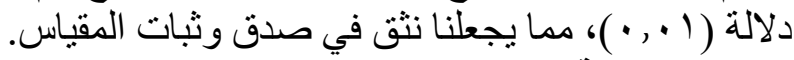

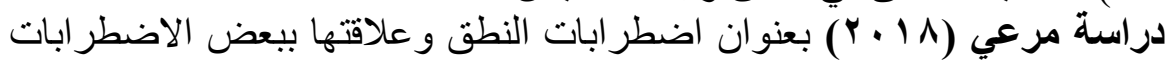

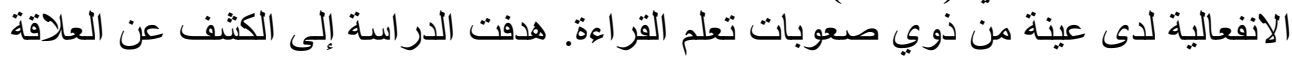

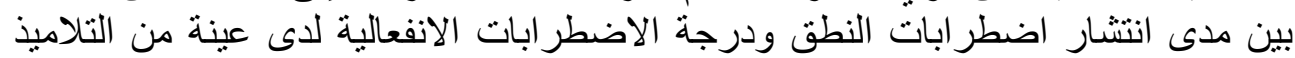

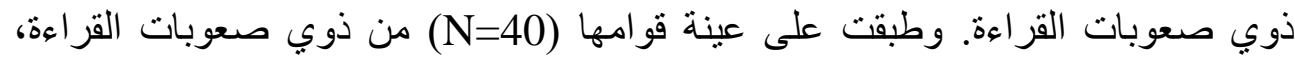

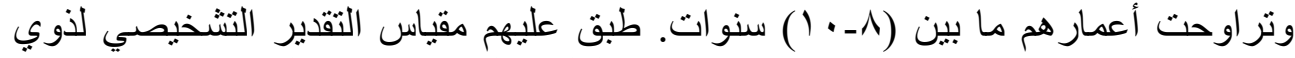

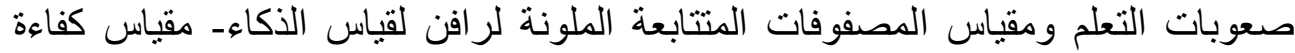

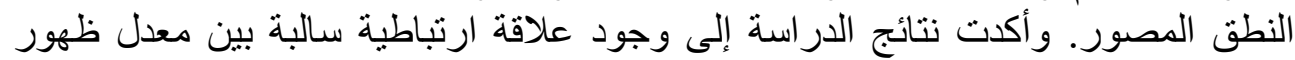

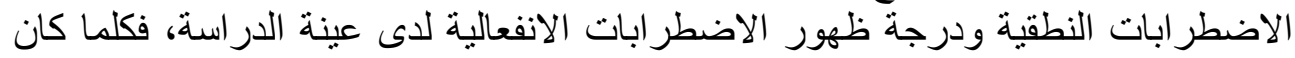

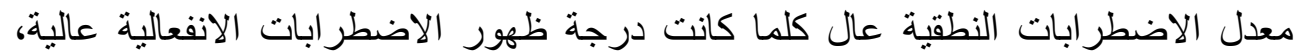

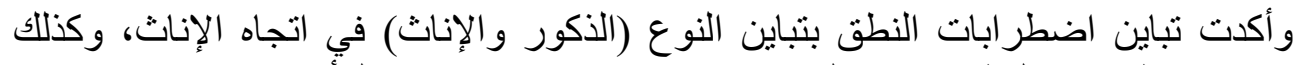

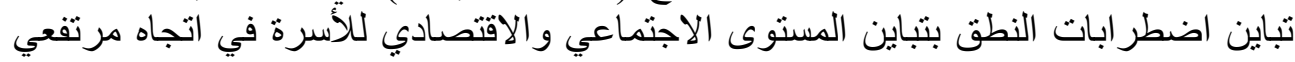

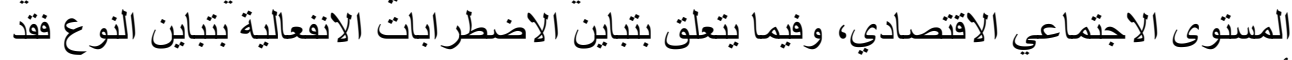

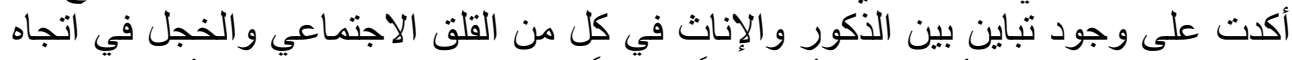

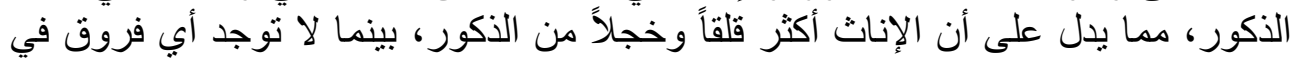

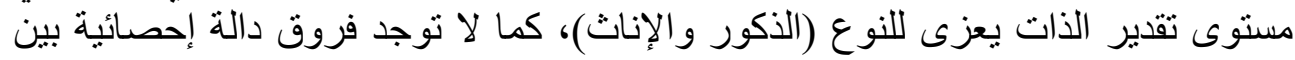

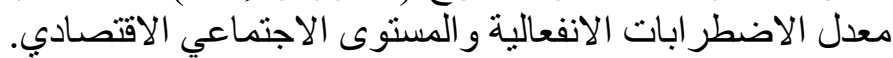

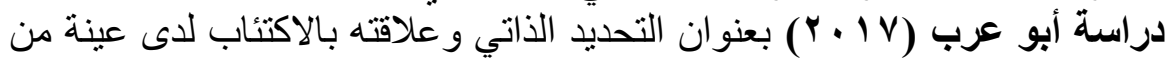

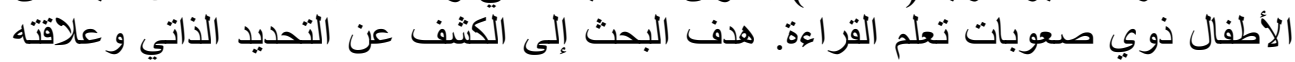

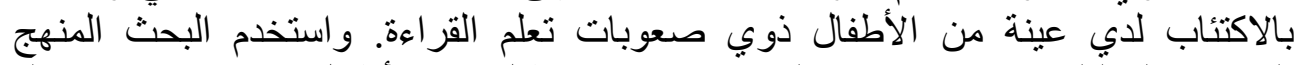

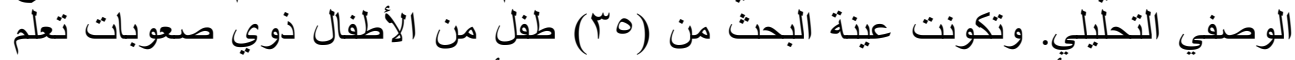

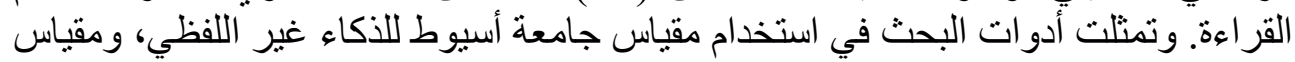

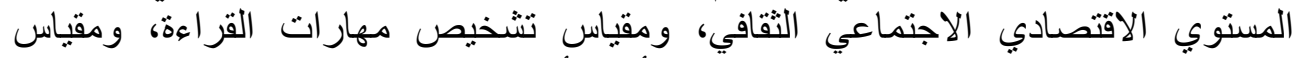

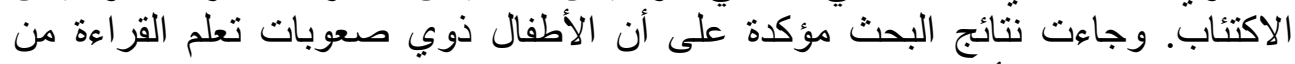

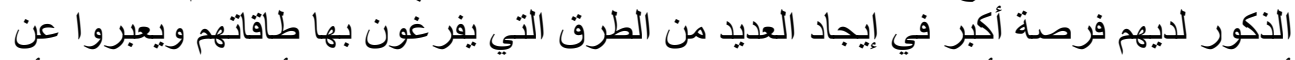

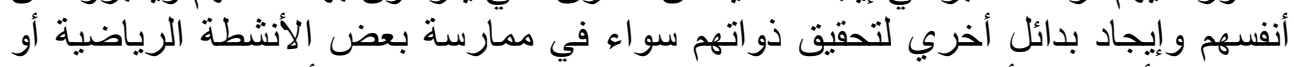

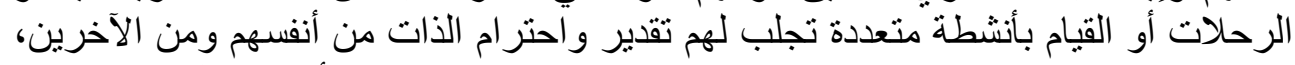

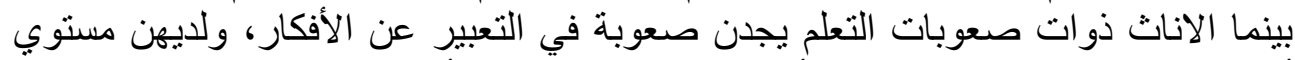

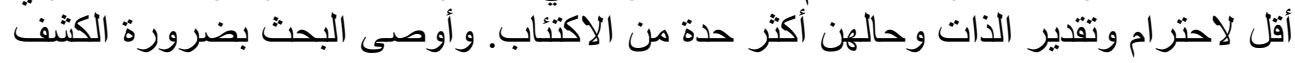

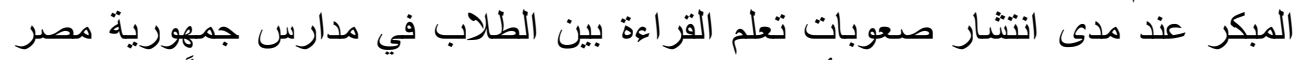
العربية، و الكثف المبكر عن الأمر اض والاضطر الترابات النفسية للطلبة عموماً والمصاحبة فئة 


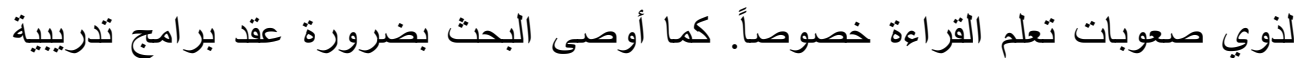

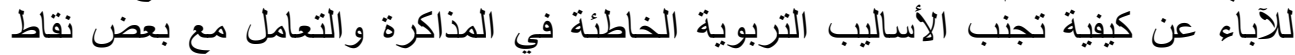

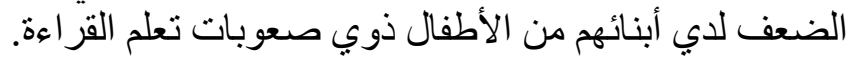

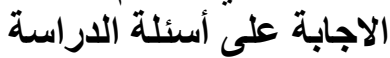
إجابة السؤال الأول/ مفهوم الألهابة كلاً من الضغوط النفسية و صعوبات التعلم

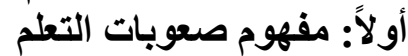

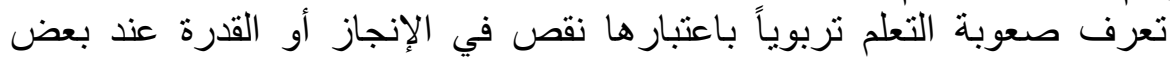

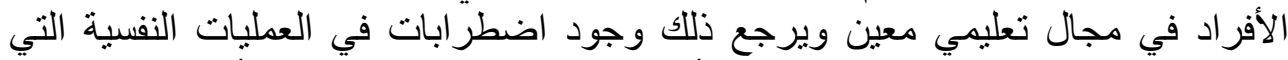

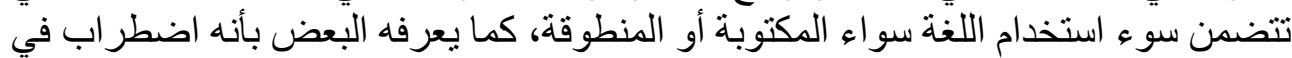

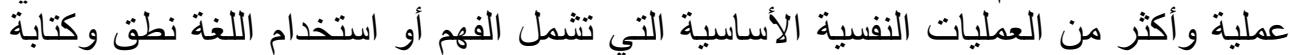

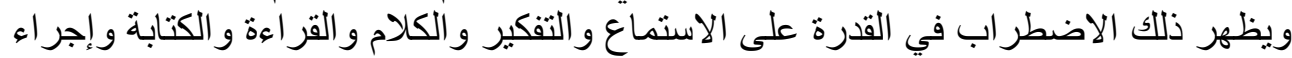
العمليات الحسابية كما يشمل التعريف إصابات المخ العز والحد الأدنى من الذكاء (سعدات، ( $($ r. $) \varepsilon$

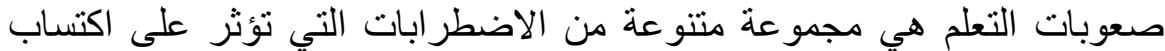

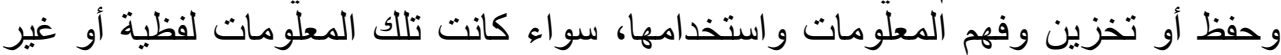

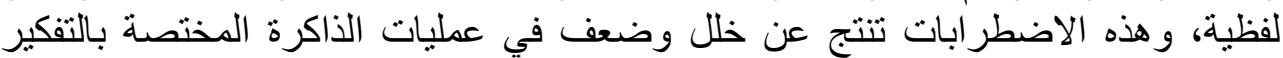

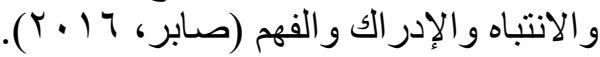

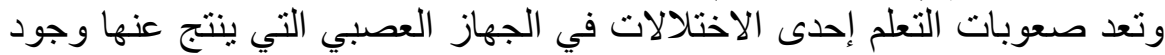

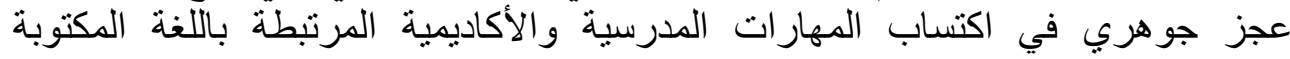

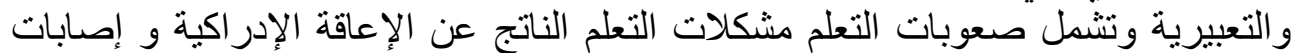

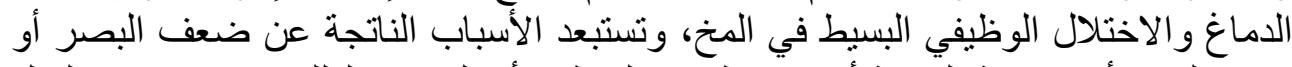

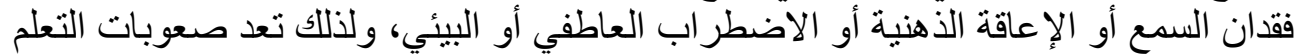

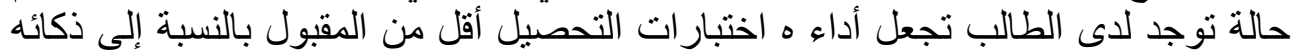

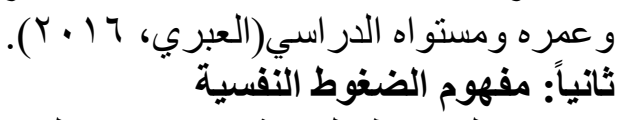

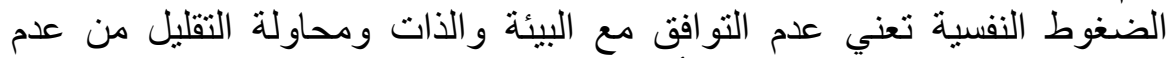

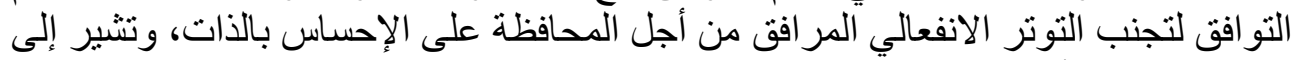

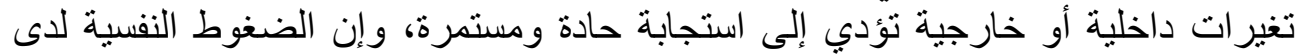

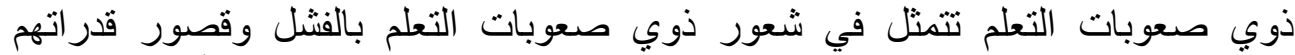

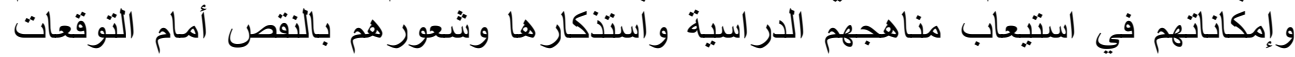

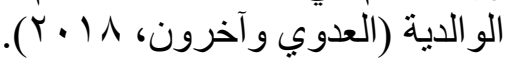


كما تم تعريف الضغوط النفسية على أنها عبارة عن الحالة التي تنتج حين يقود

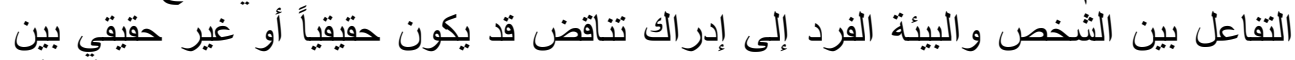

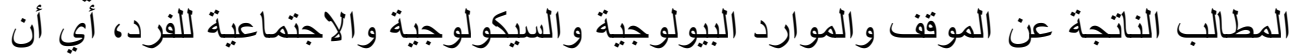

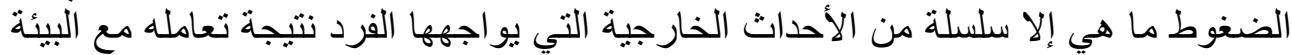

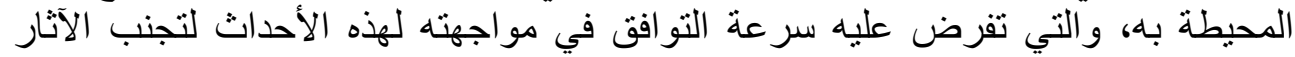

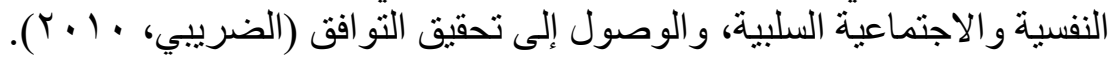

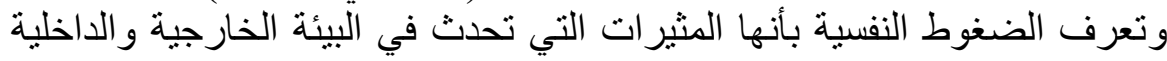

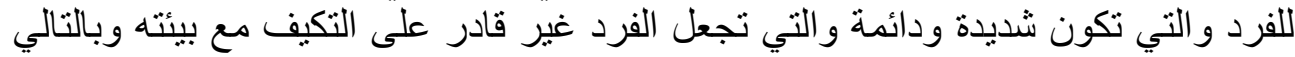

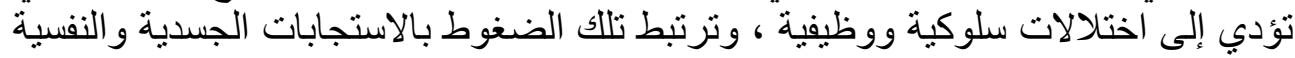

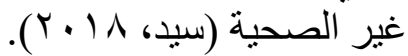

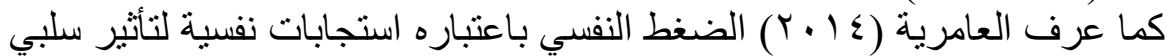

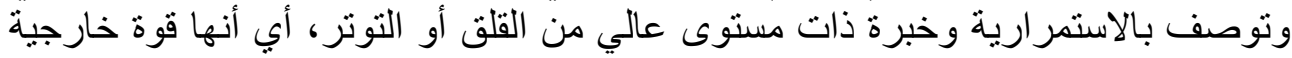

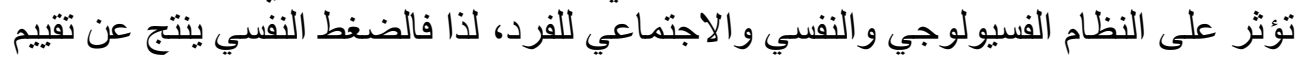

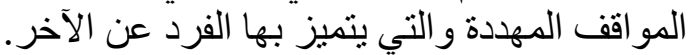

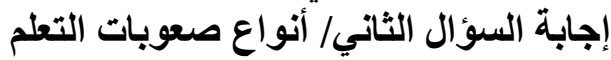

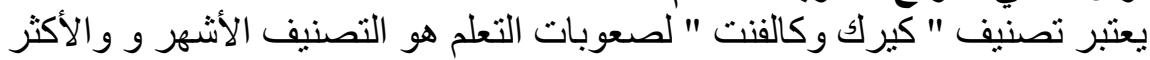

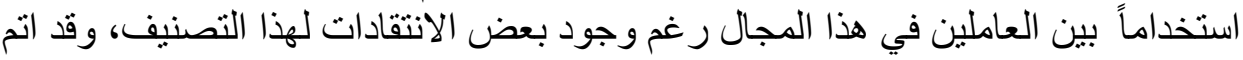
تقسيمه إلى نو عين هما:

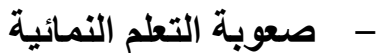

نجد أن صعوبة التعلم النمائية ترجع إلى اضطئة التهر ابات وظيفية في الجهاز العصبي

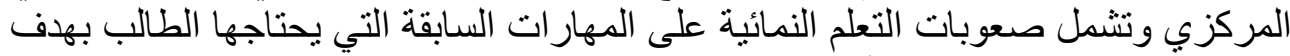

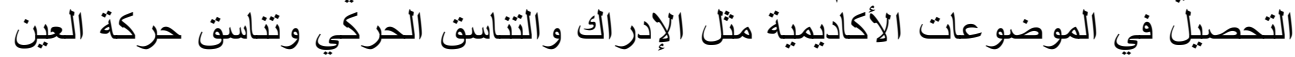

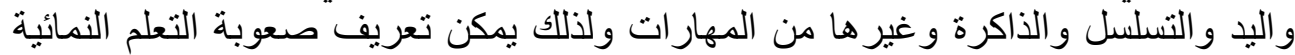

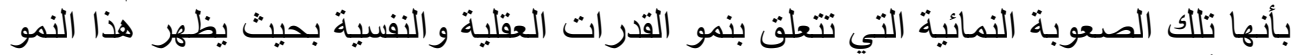

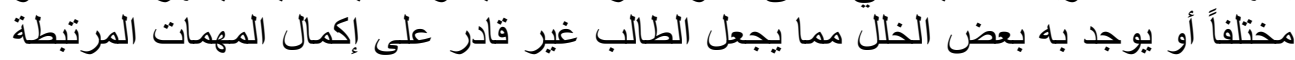

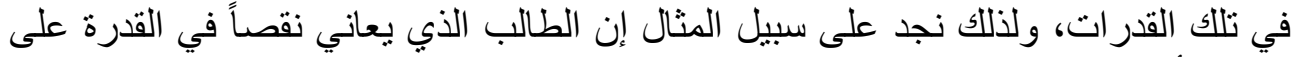

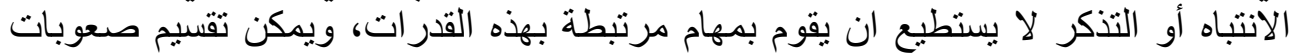

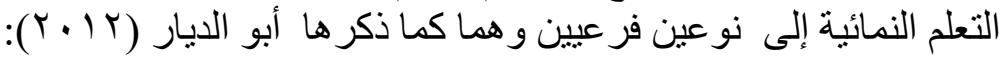
- - صعوبات أولية: مثل الانتباه و الادر الك و الذاكرة. - - معوبات ثنانوية: مثل التفكير و الكلام و الفهم و اللغة الثففوية. - - صعوبة التعلم الأكاديمية 


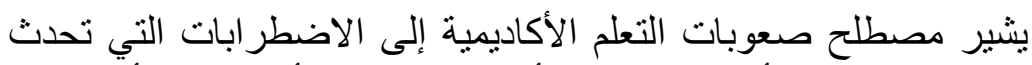

في عملية التعلم مثل القراعة أو عملية الكتابة أو عملية التهجي التئي أو الحساب أو أو التعبير

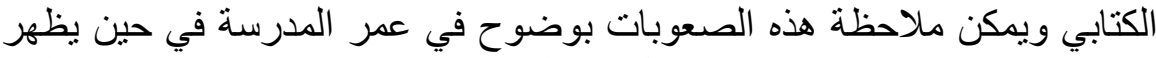

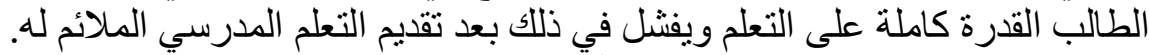
كما يوجد بعض التصنيفات لصعوبات التعلم وفقاً لنوعها إلى الصى

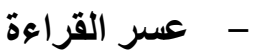

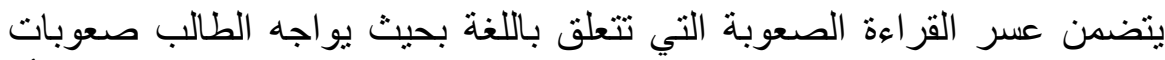

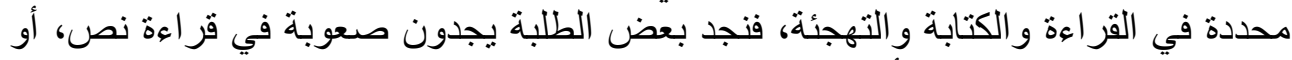

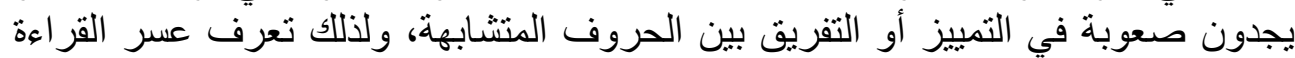

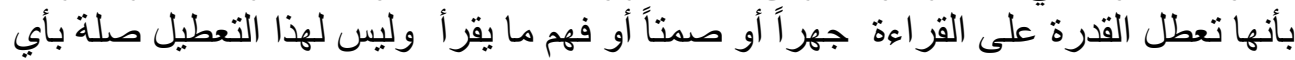

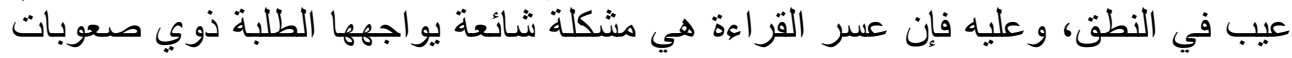

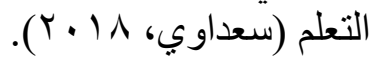

-

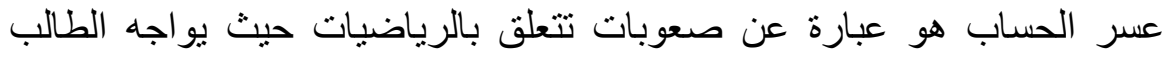

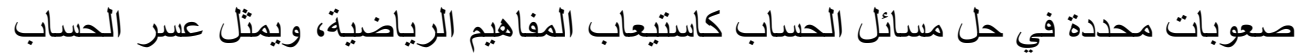

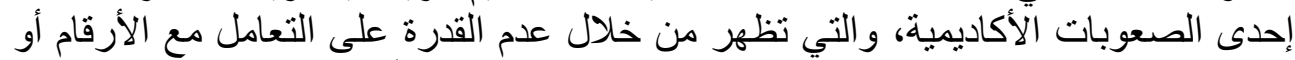

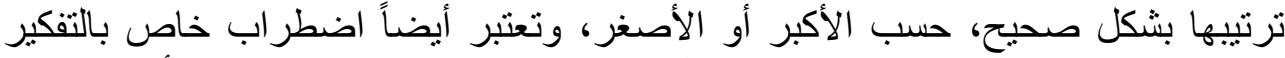

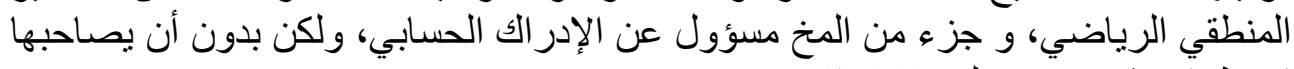

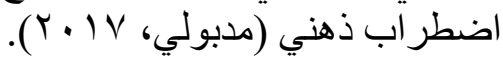
و ون مظاهر التعسر الحسابي لدى الطلبة هو الفتشل في تحديد العلاقات المكانية مثل

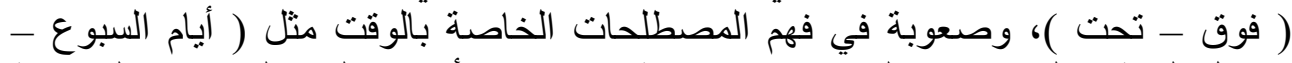

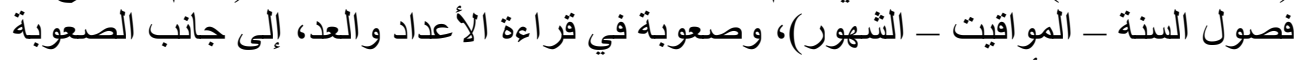

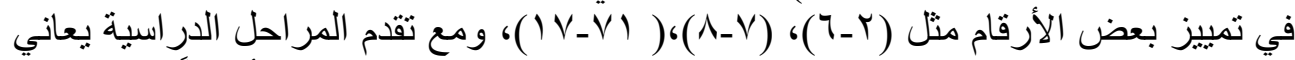

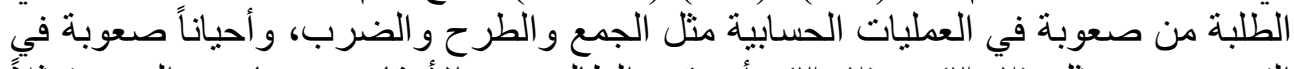

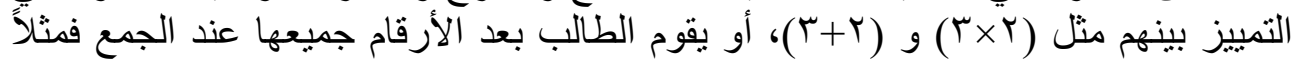

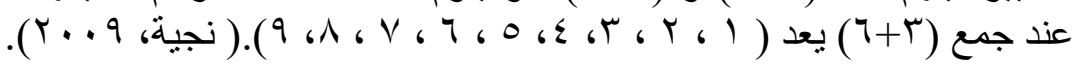
- - عسر الكتابة

تعد صعوبات الكتابة من صعوبات التعلم التي لها دور أساسي في التحصيل

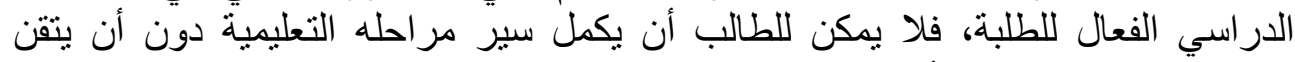

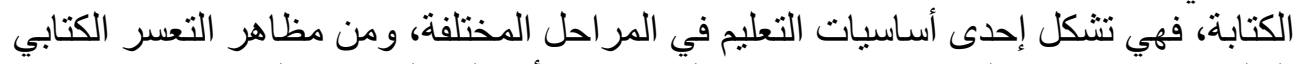

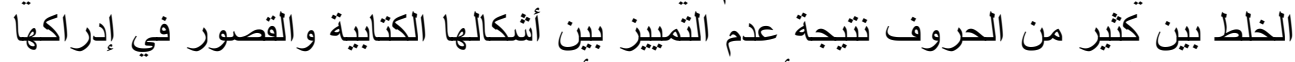

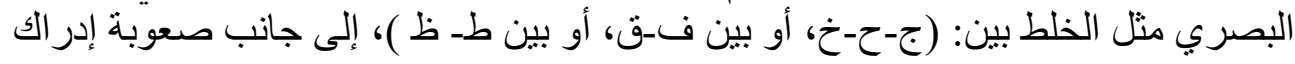


التطابق الفعلي بين عدد من الأصو ات و الحروف مثل: ص بدل س، أو د بدل ضه، أو ت بدل بدل

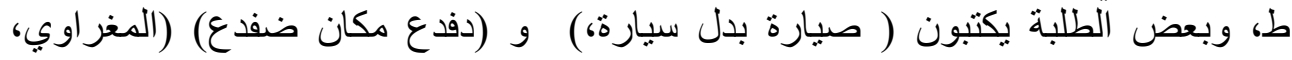
. ( $($. IV

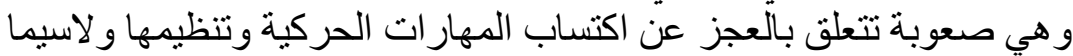

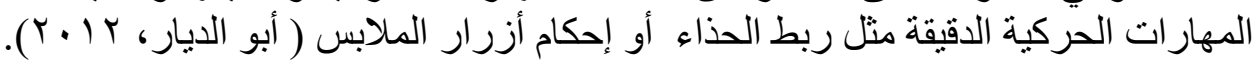

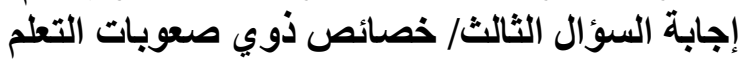

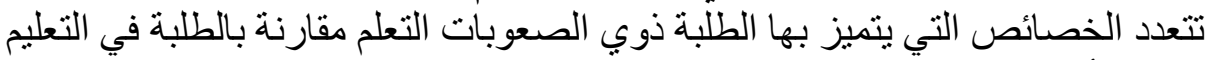

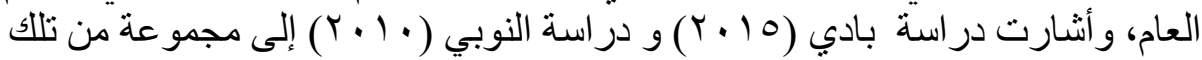

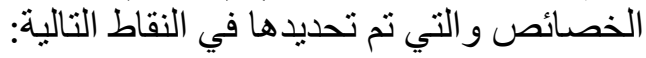

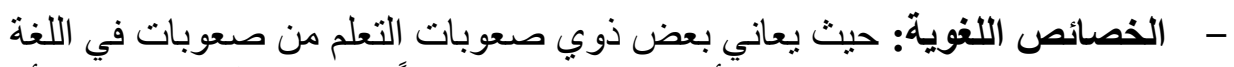

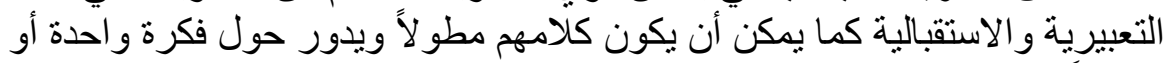

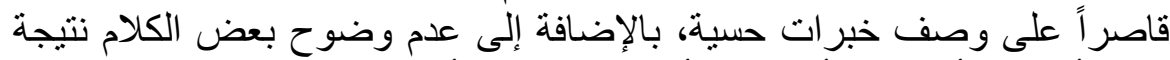
حذف أو إبدال أو تثويه أو إضافة أو تكرار لبعض الإض أصوات الصف الحروف.

\section{- - مالخصائص الحركية:}

مشكلات في التوازن وتظهر التهر على شكل مشكلات في المشي كارتطامه بالأشياء

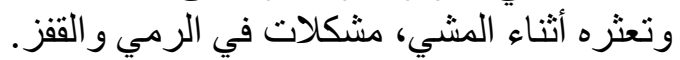

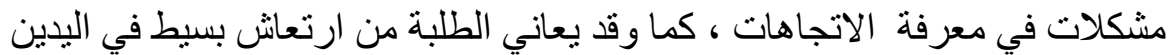

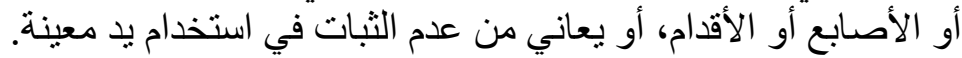

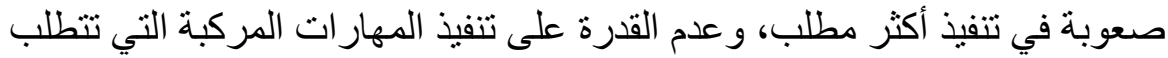

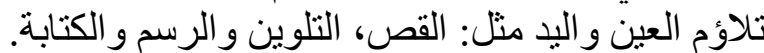

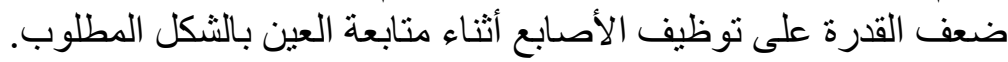

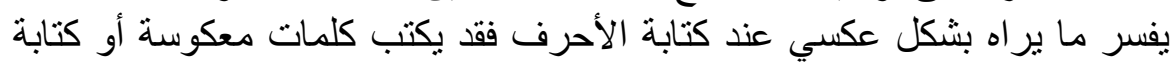

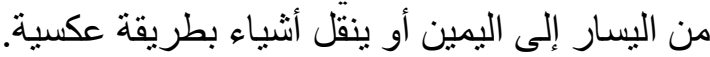

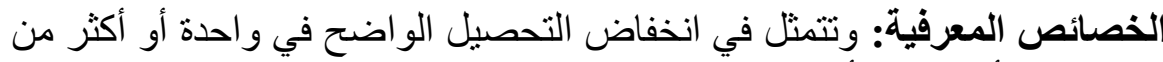

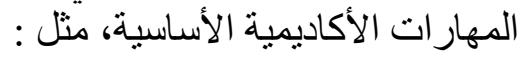
صعوبة في القراعة بصوت مرتفع واضح وكثير ما يتم حذف أو زيادة بعض الاض الكلمات. صعوبة في استخر اج المفاهيم الأساسية في فقرة مكتوبة.

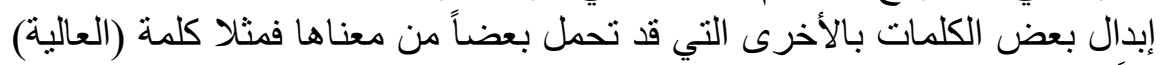
بدلاً من الكلمة (المرتفعة). 
قلب الأحرف وتبديلها، وضعف في التمييز بينها عندما تتشابه رسماً مثل: (ع، غ) و

ضعف في التمييز بين أحرف العلة مثل قراءة كلمة ( فول) ( فيل).

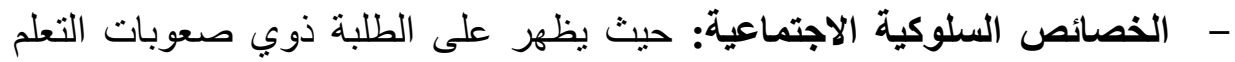

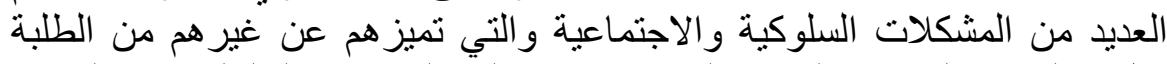

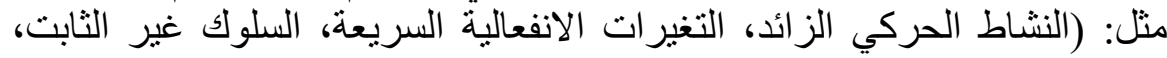

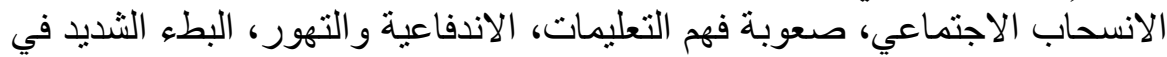

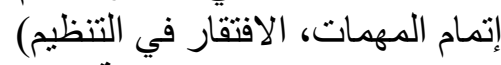

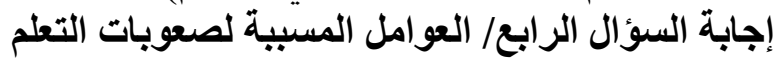

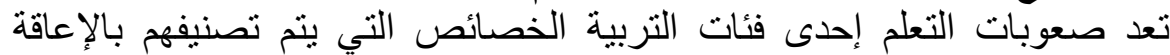

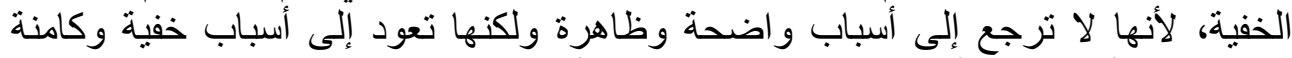

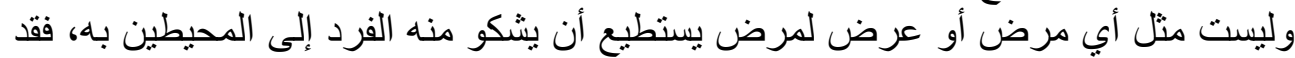

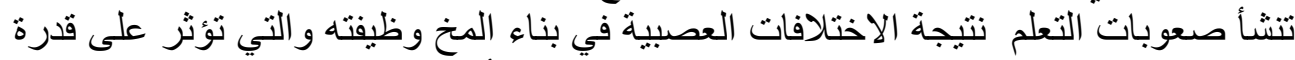

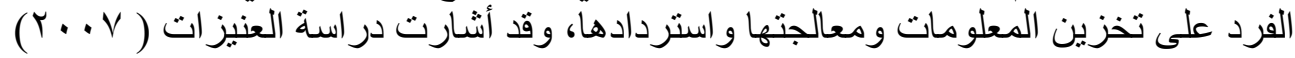

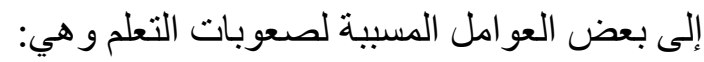

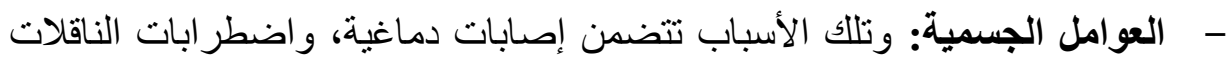

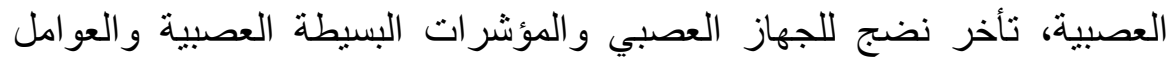

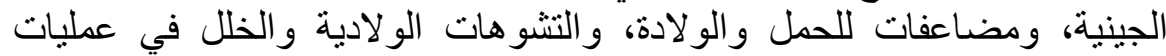

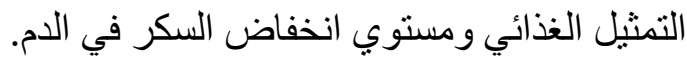

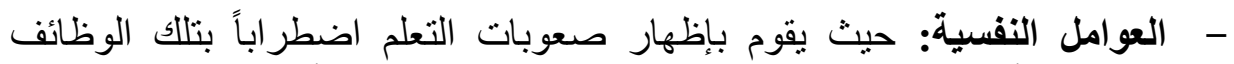

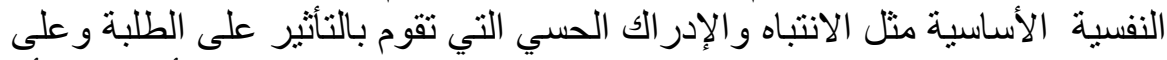

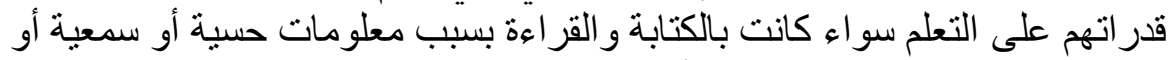
بصرية لا يتم علاجها بشكل كامل أو صحيح.

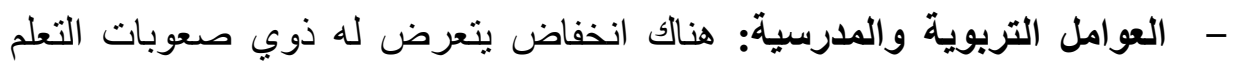

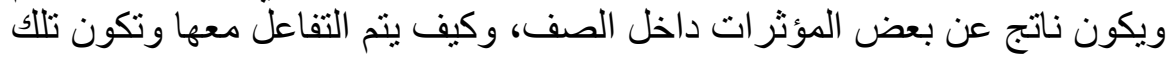

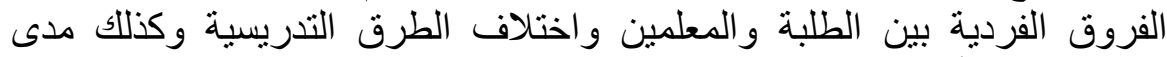

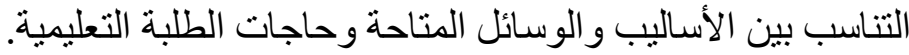

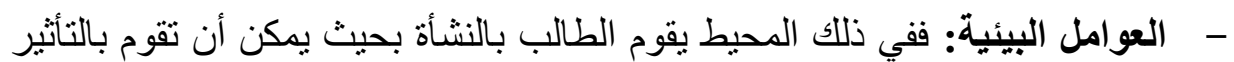

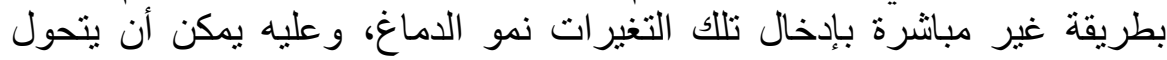

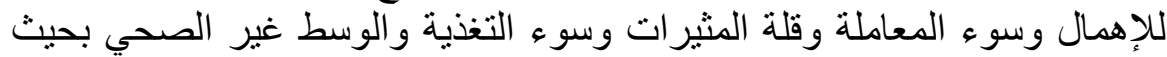


يقوم بالانعكاس على النمو داخل الجهاز العصبي المركزي مما ينتج عنه عدم قدرة

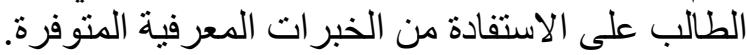

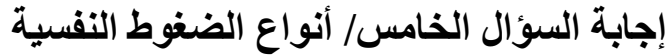

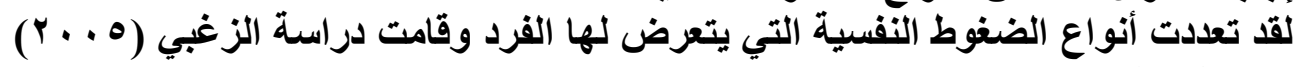

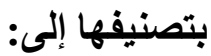

- - الضغط النفسي السيء: الذي يجعل على الفرد منطلبات زائدة ويطلق عليه الكرب. - - الضغط النفسي الجيد: والذي يتمثل في منطلبات إعادة التكيف مثل و لادة طفل، لأل السفر. - - الضغط النفسي المنففض: الذي يحدث عندما يشعر الفرد بالممل، انعدام الإثارة

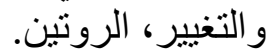

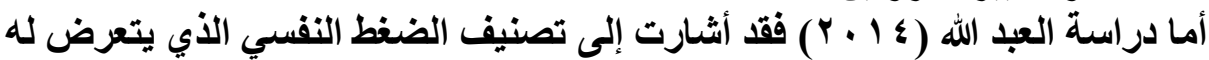
الفرد وهو كالتالي:

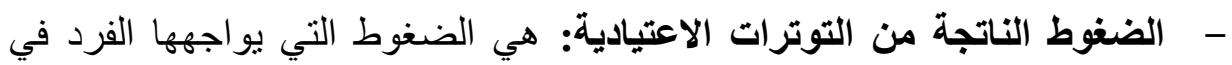

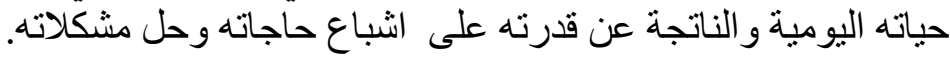

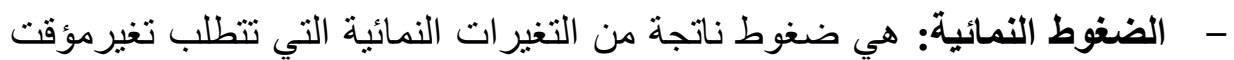
في أسلوب الحياة المعتاد.

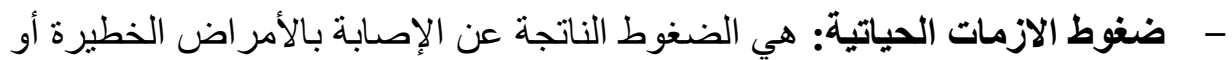

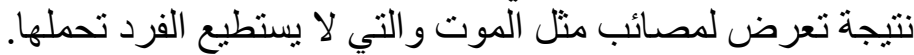

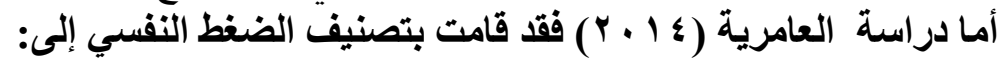

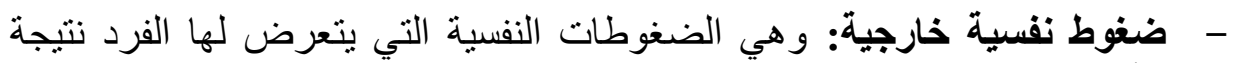

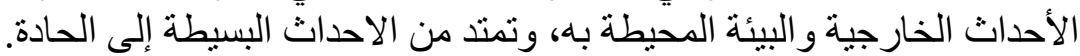

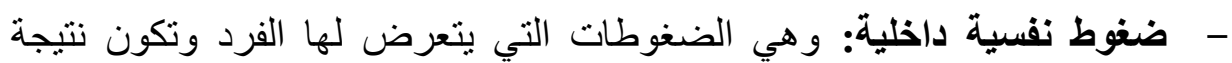

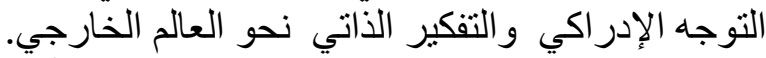

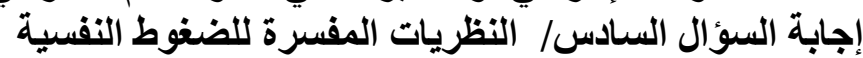

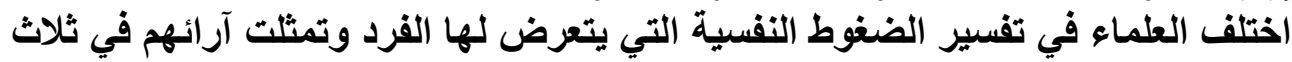

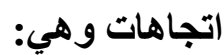

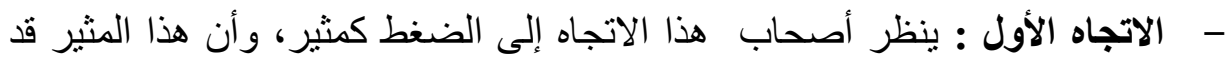
يكون داخلي مثل الصر اعات، وقد يكون خارجي من البيئة المحيطة.

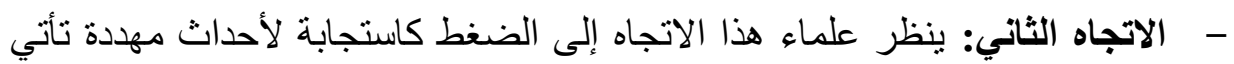
من البيئة. 
- الاتجاه الثالث: هو الاتجاه التفاعلي أي تفاعل الفرد مع بيئته، بحيث أن الضغط الضئل يحدث عندما تتجاوز المطالب البيئية مصادر الفرد وإيكانات الباته للمواجهة (العامرية،

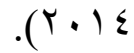

وبناءً على ذللك ظهرت عدة عان نظريات مختلفة لتفسير الضغوط النفسية ومنها:

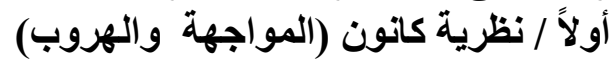

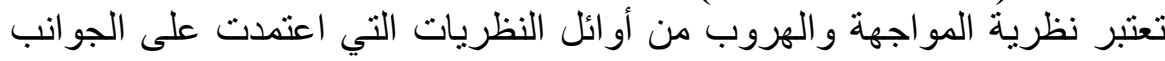

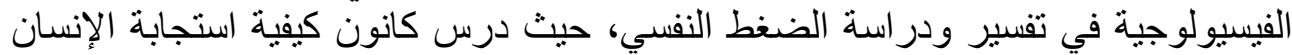

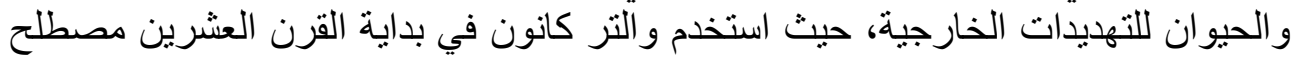

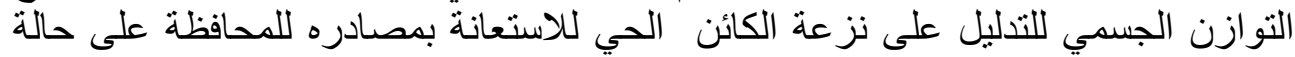

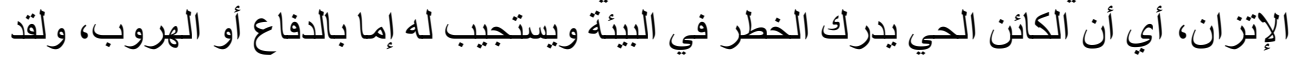

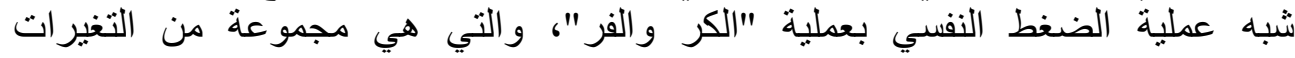

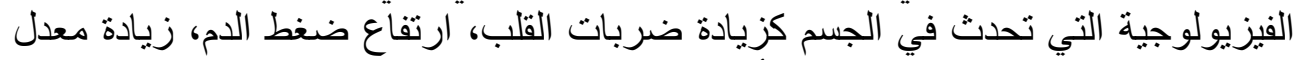

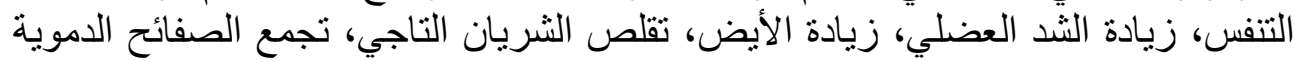

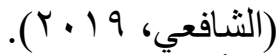
ثانياً / نظرية سيلية

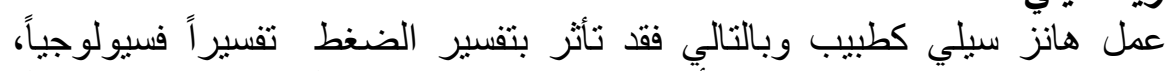

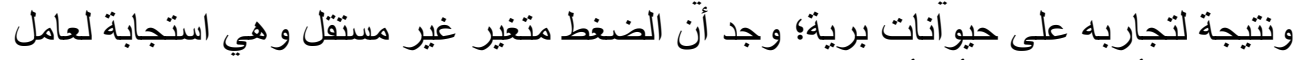

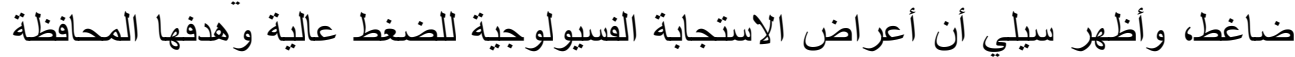

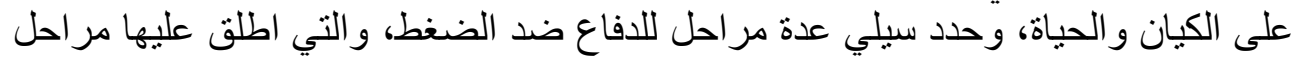
التكيف العام وهي الان والياه

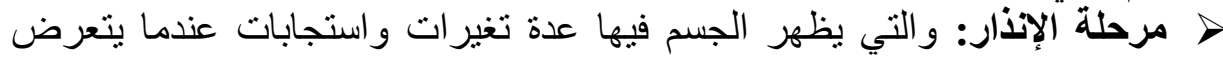

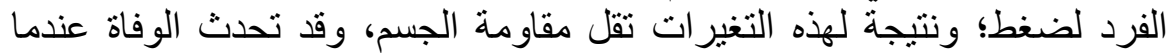

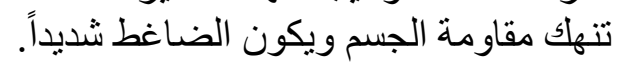

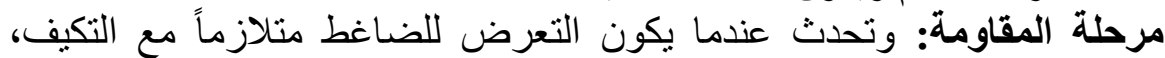

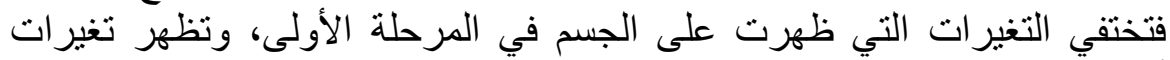

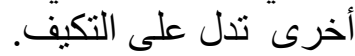

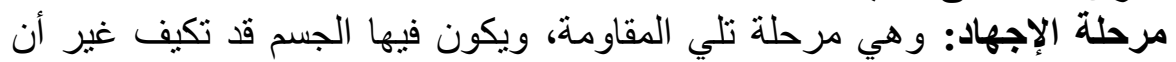

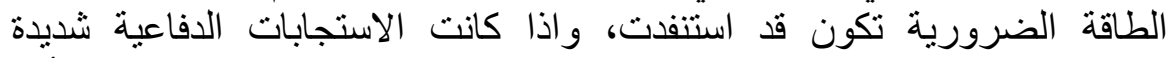

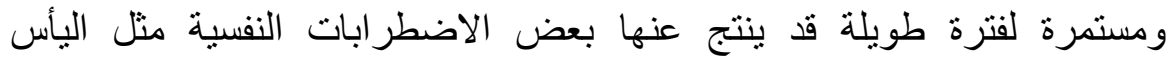

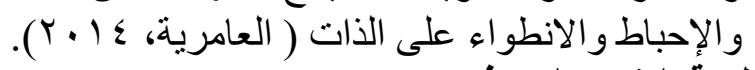
ثالثاً / نظرية التقدير المعرفي لازاروس علئ 


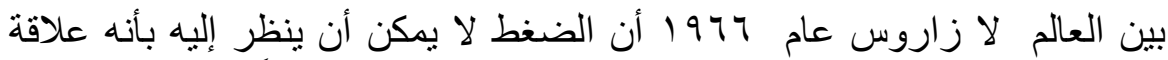

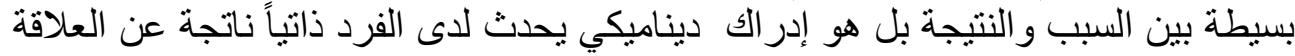

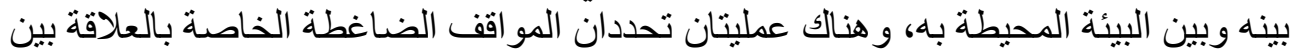
الفرد و البيئة و هين البئة البئ 1 - عملية التقدير العقلي المعرفي: وتشمل عملية التقدير المعرفي نوعين أساسيين من

$$
\text { التقدير وهما: }
$$

التقدير الأولي الذى يحكم على الوضعية الموجود فيها الفرد ما إذا كانت ضاغطة أم

التقدير الثانوي الذى يعمل على تقويم الوسائل البديهة لمواجية الخطر المدرك.

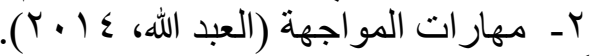

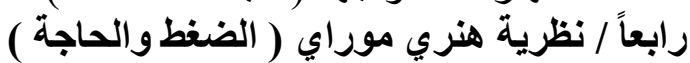

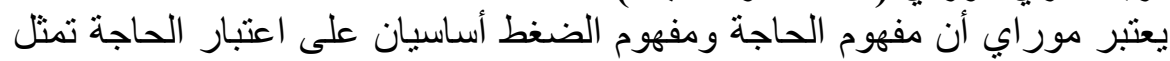

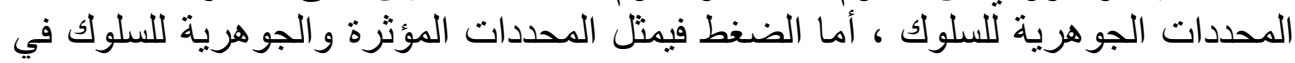

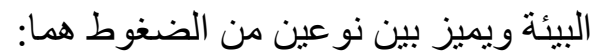

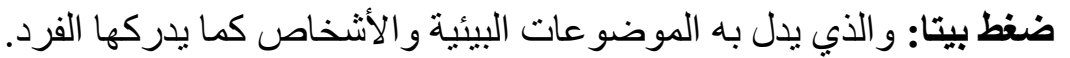

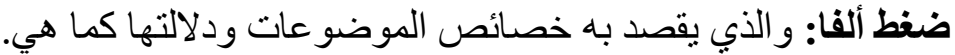

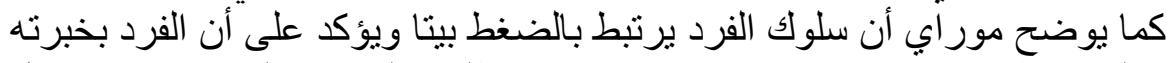

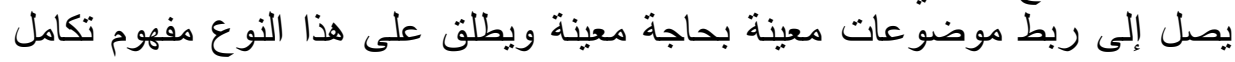

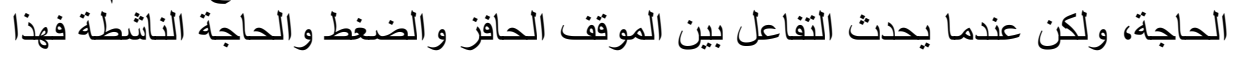

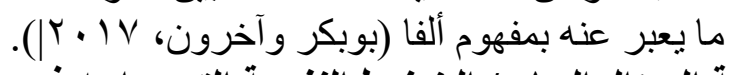

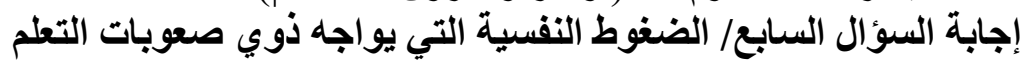

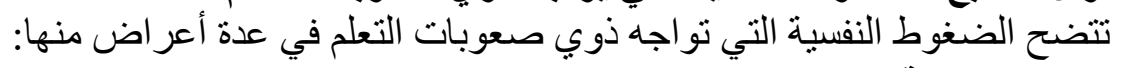

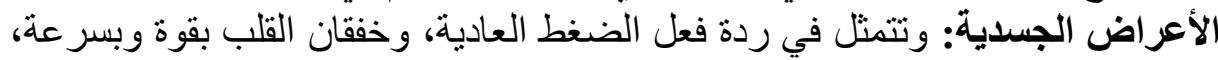

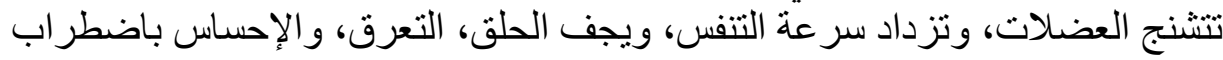
في المعدة. الاعراض الذهنية: والتي تتمثل في صعوبة في التركيز، تتنت الانتباه.

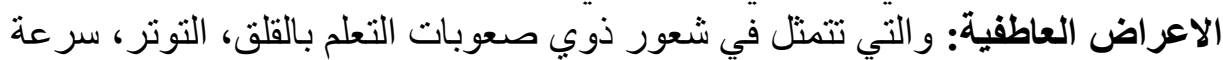

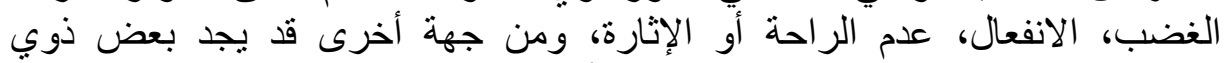
صعوبات التعلم متباطنين، محبطين، حزينين الانين أو أو كئيبين.

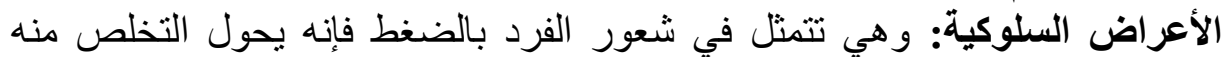

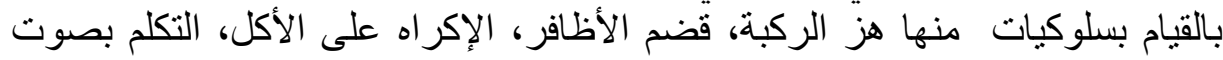

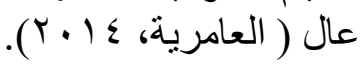


اجابة السؤال الثامن/ أساليب مواجهة الضغوط النفسية

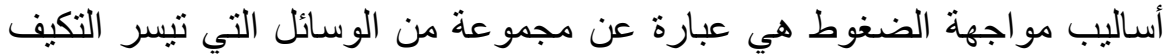

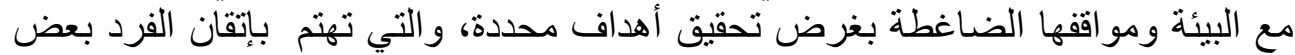

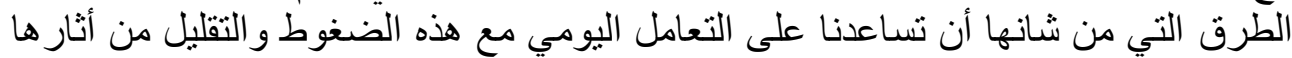

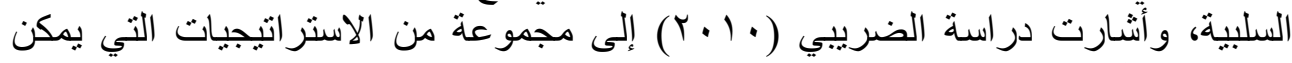

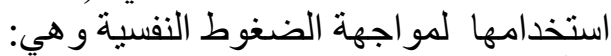

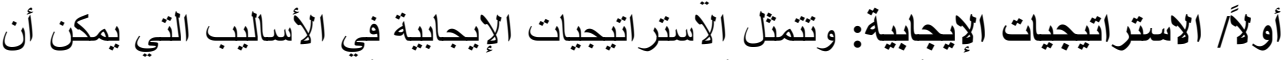

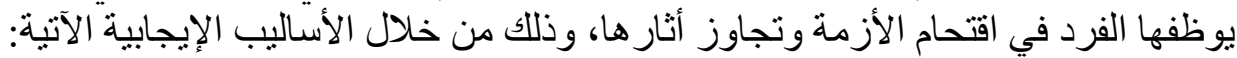

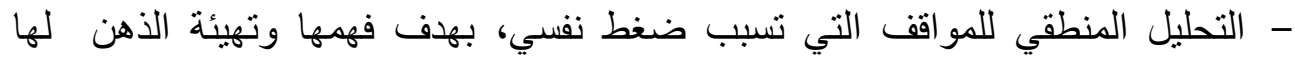
ولمرتباتها.

- إعادة التقييم الإيجابي للموقف حيث يحاول الفرد معرفياً استجلاء الموقف و إعادة بنائه

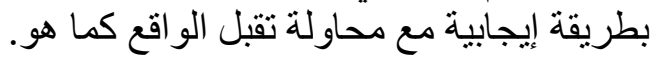

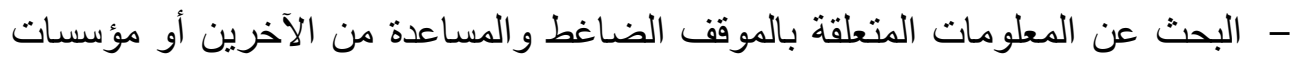

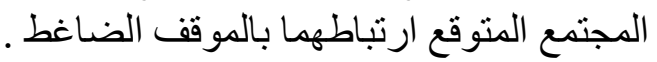

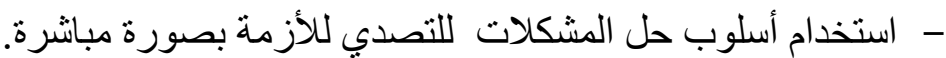

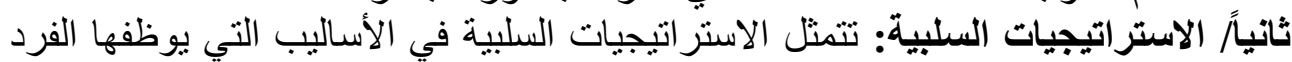

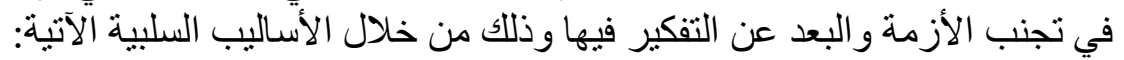

$$
\text { - الابتعاد عن التفكير الواقعي في الأزمة. }
$$

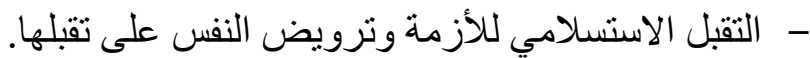

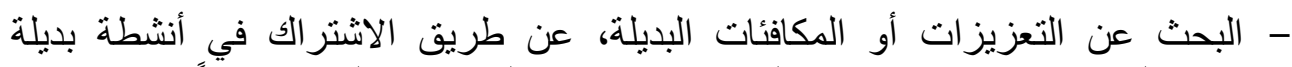

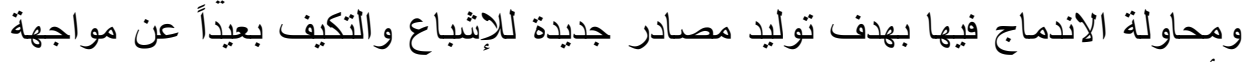
الأزمة. - التفيس والتفريغ الانفعالي بالتعبير لفظياً عن المشاعر السلبية غير السارة، وفعلياً عن

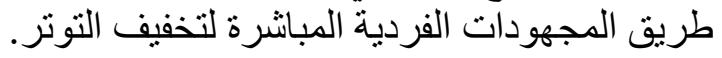

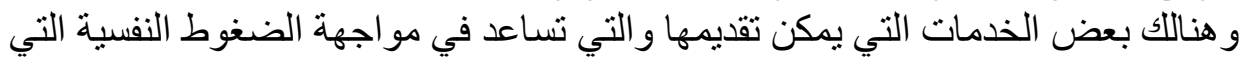

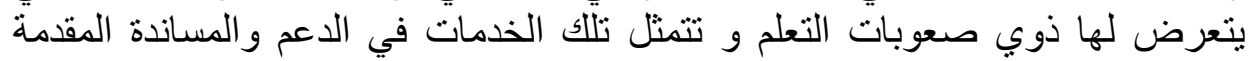

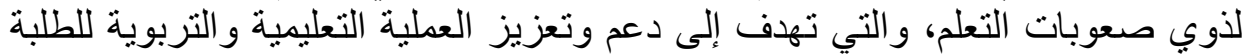

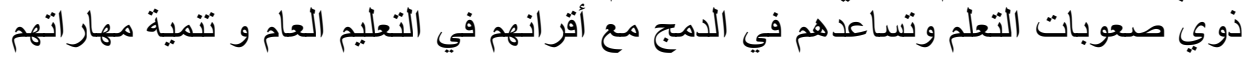
و إمكاناتهم وتشمل عدة خدمات وهي: 


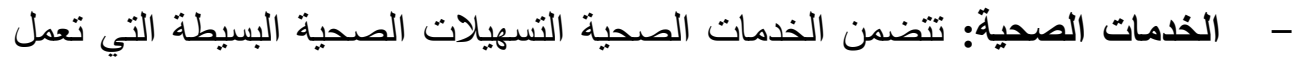

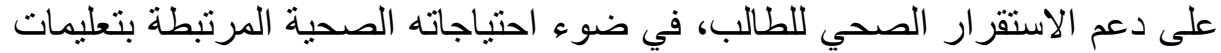

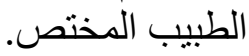
الخدمات النفسية: تتعلق الخدمات النفسية بعمليات التشخيص و التقويم للطلاب من ذوب التوبي

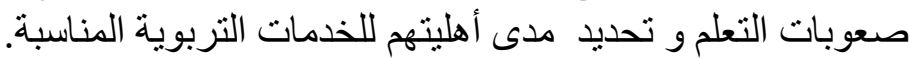

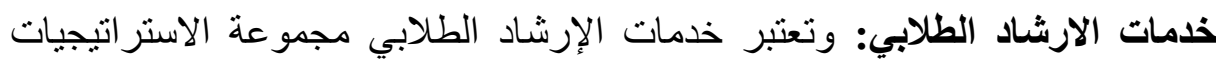

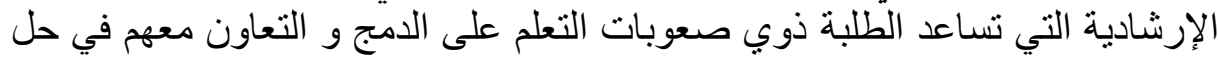

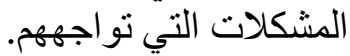
خدمات علاج النطق والكلام: تتضمن خدمات علاج النطق واتهات والكلام تشخيص حالات

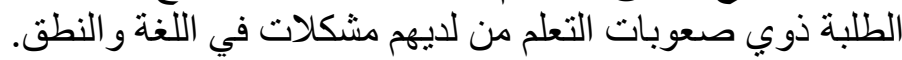

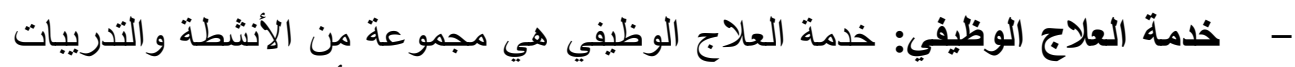

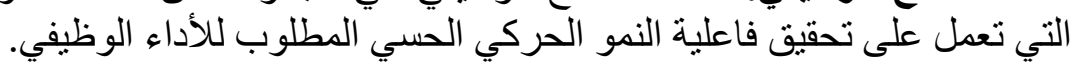

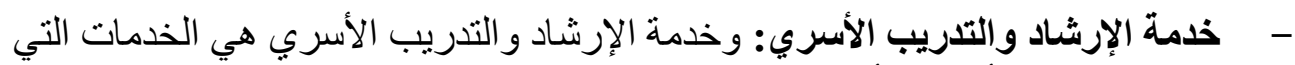

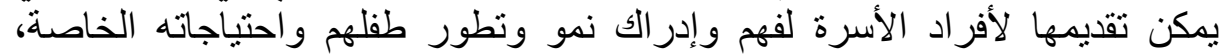

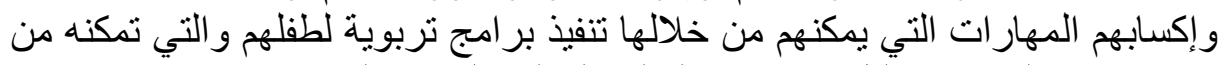

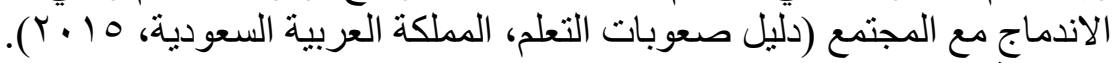
نتائج الاراسة

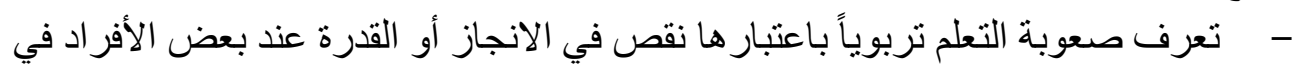

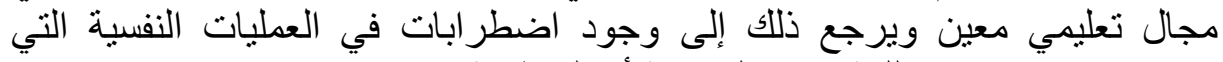

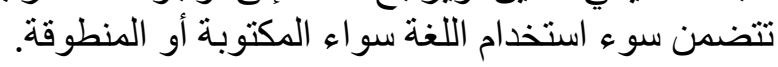

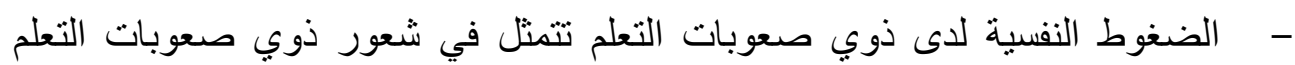

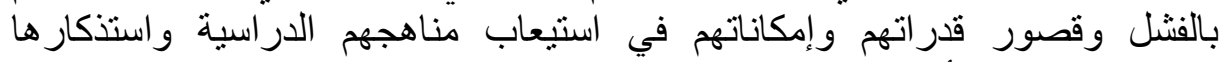
وشعور هم بالنقص أمام التوقعات الوراته والدية.

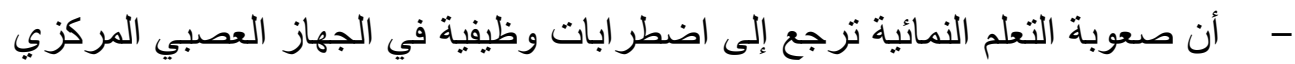

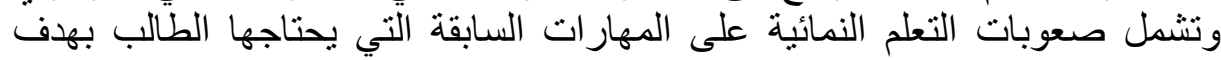

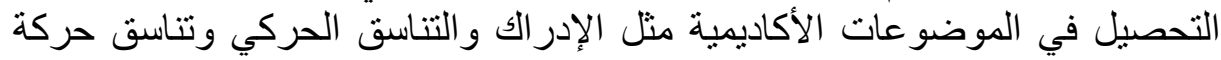
العين و اليد والتسلسل و الذاكرة.

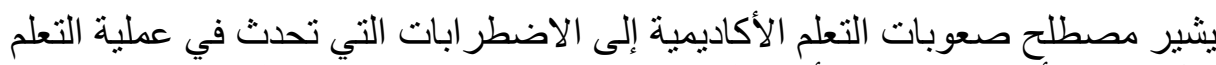

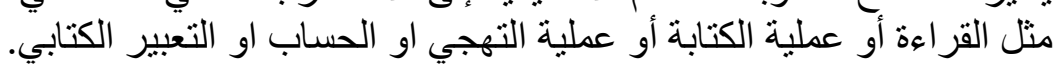


- - تتعدد الخصائص التي يتميز بها الطلبة ذوي الصعوبات التعلم مقارنة بطلبة بالتعليم العام و تنها خصائص لغوية و أخرى حركية وخصائص معرفية التهلية وسلوكية و اجتماعية.

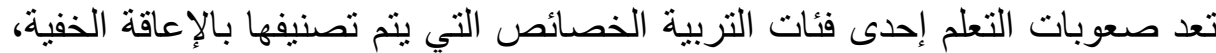

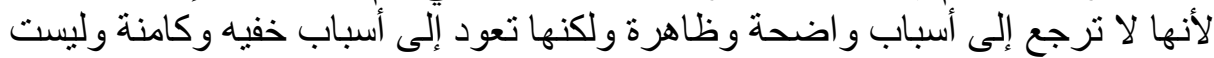

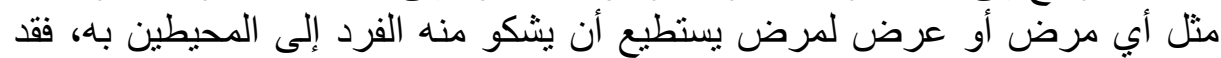

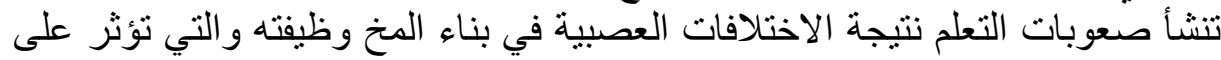
قدرة الفرد على تخزين المعلومات ومعالجتها واستر التعردادها.

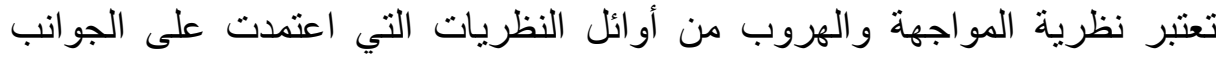

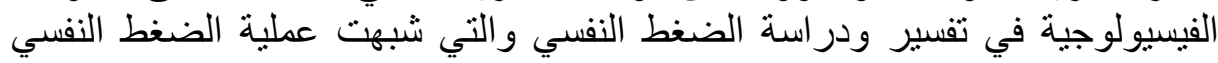

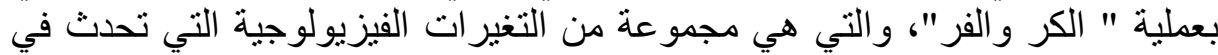

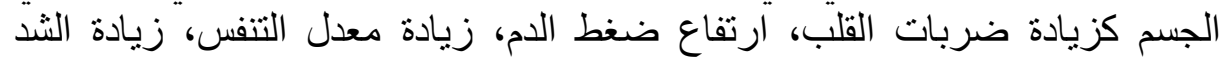
العضلي، زيادة الأيض، تقلص التص الثريان التاجي، تجمع الصفائح الدموية.

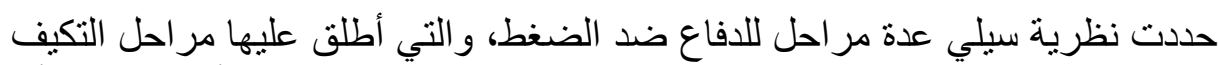

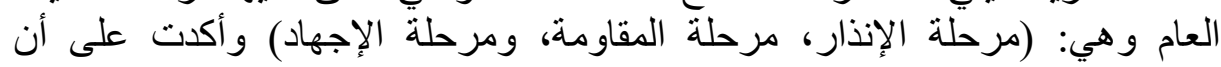

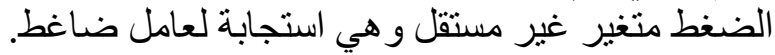

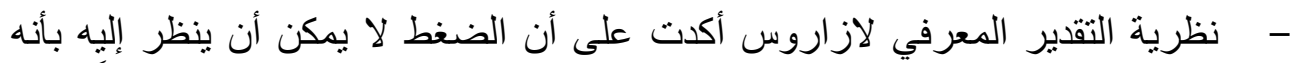

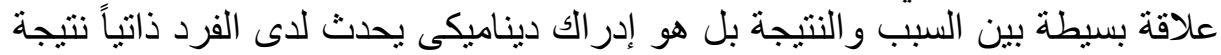

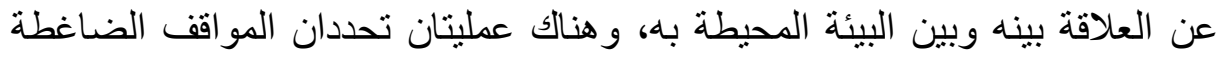

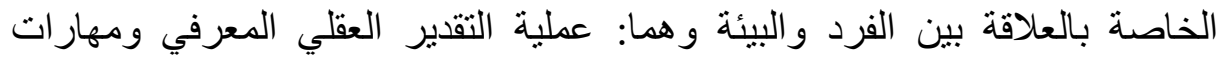
المواجهة.

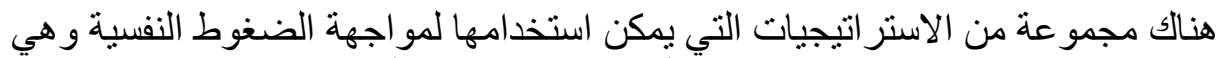

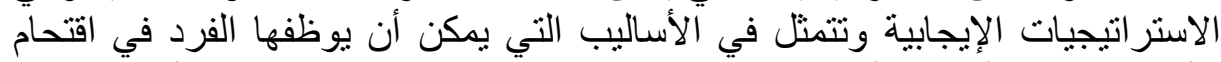

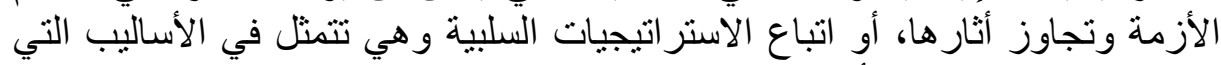
يوظفها الفرد في تجنب الأزمة والتهاع البعد عن التفكير فيها. الخلاصة والتوصيات

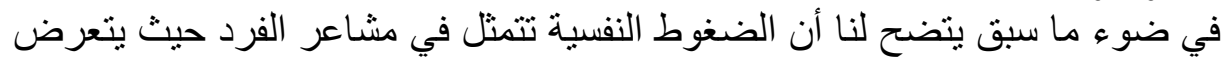

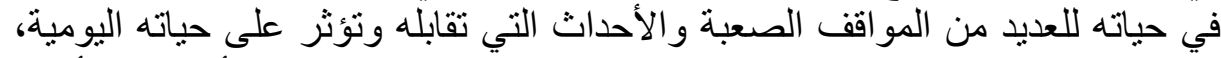

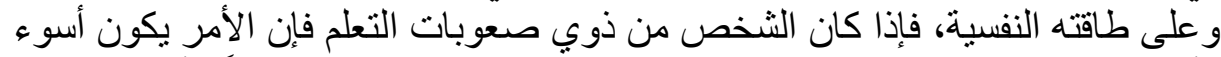

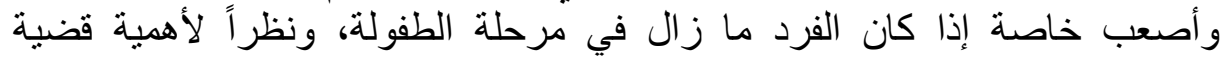

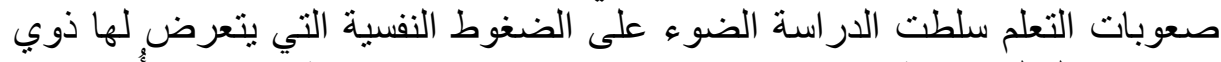

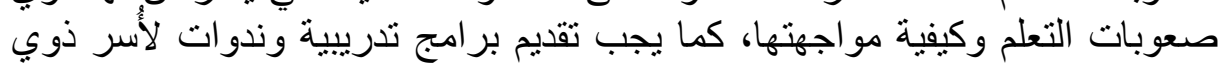


صعوبات التعلم لتأهيلهم حول كيفية معالجة الضغوط النفسية التي يتعرض لها أبنائهم

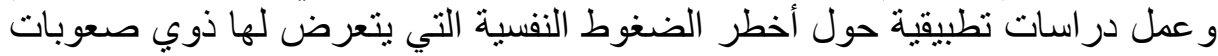

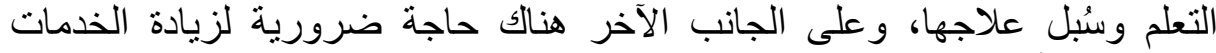

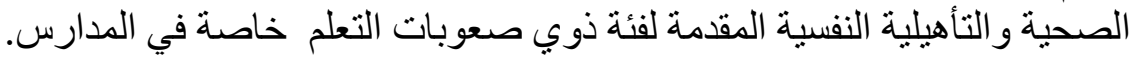




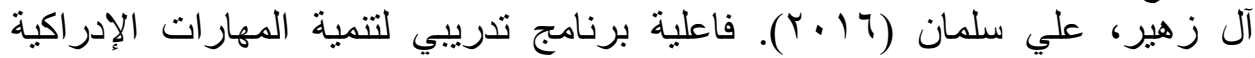

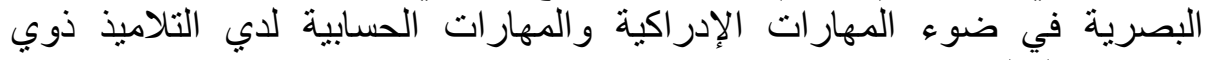

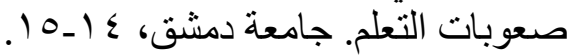

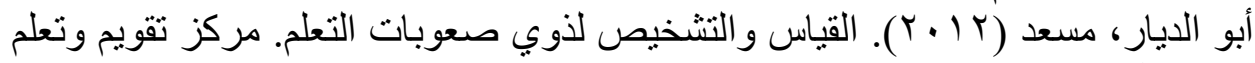

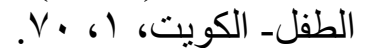

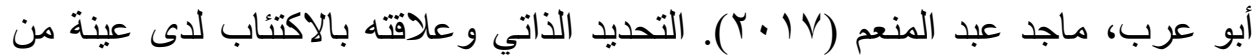
الأطفال ذوي صعوبات تعلم القر اءة. جامعة عين شمس - كلية البنات للآداب و العلوم و التربية.

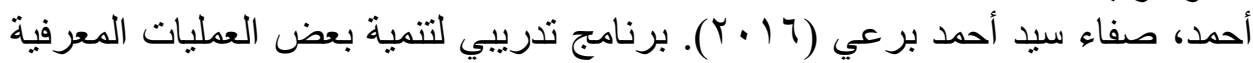

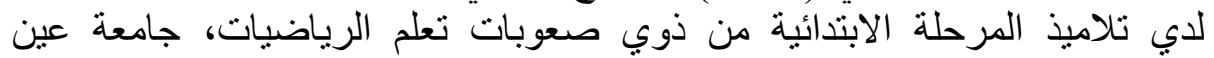
شمس، با.

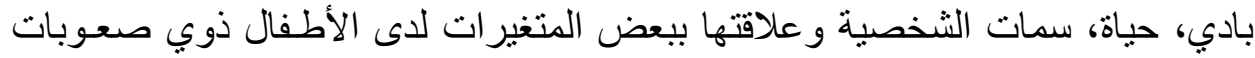

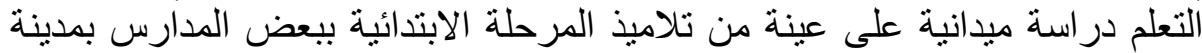

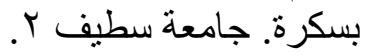

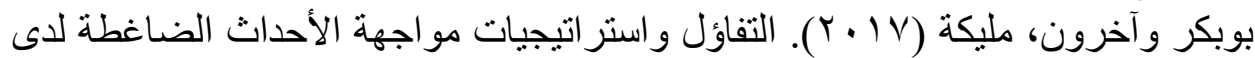

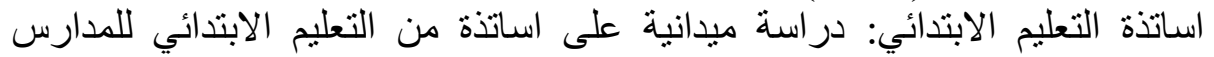

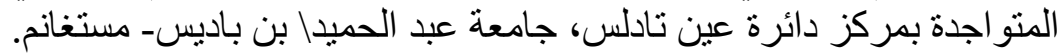

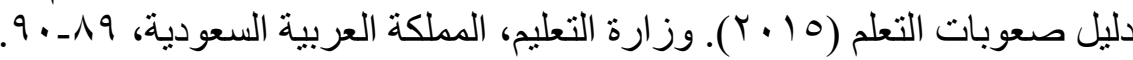

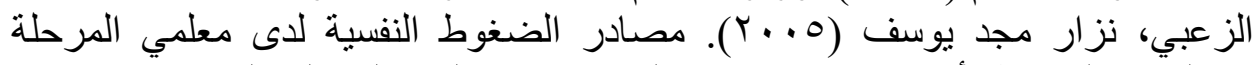

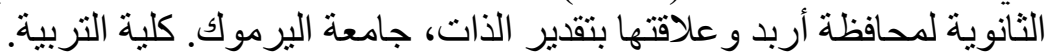

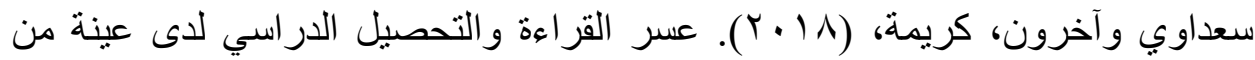

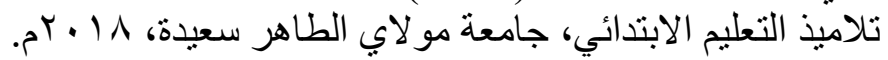

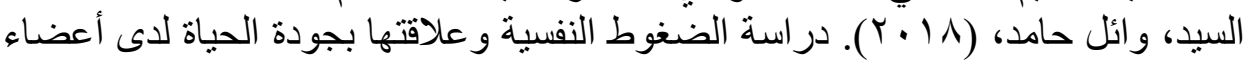

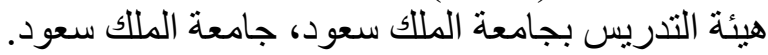

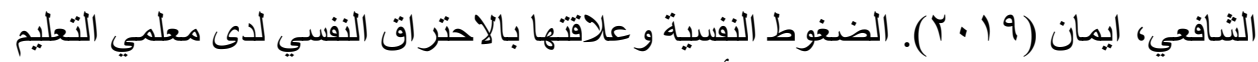

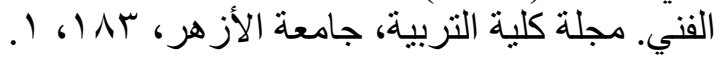

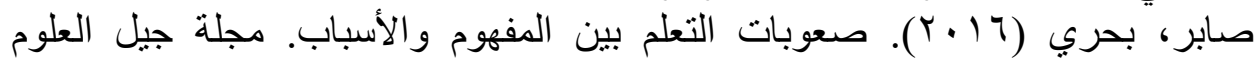

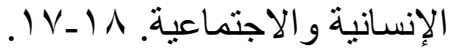

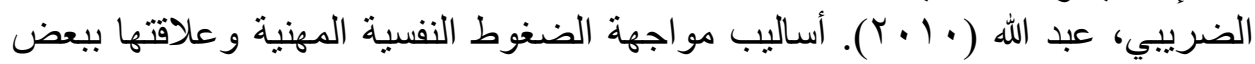

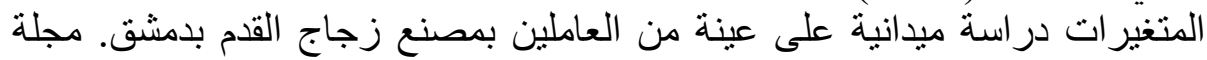

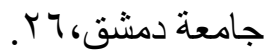


العامرية، منى عبد الله (ع ( • ب). أبعاد مفهوم الذات لدى العاملات وغير العاملات

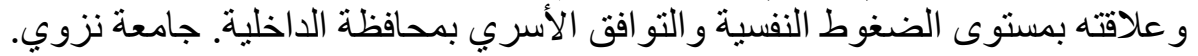

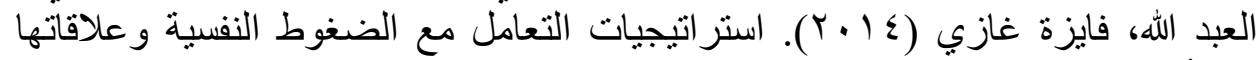

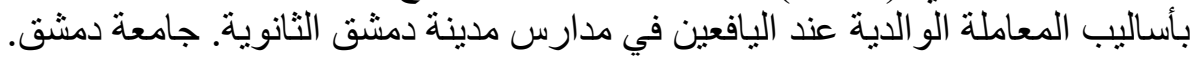

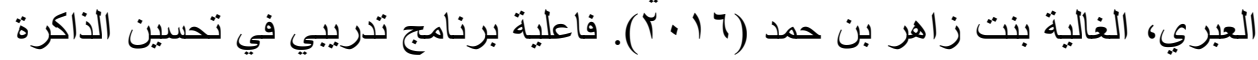

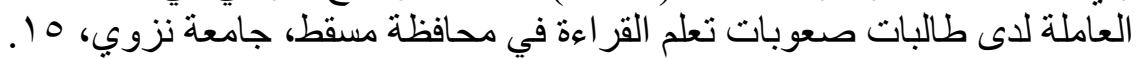

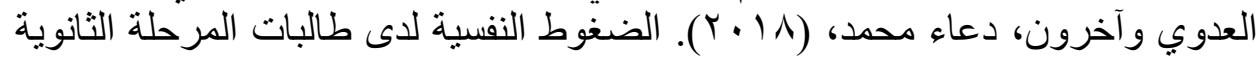

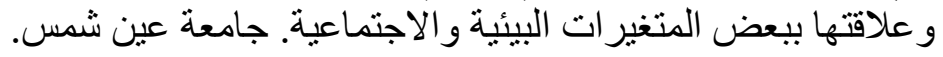

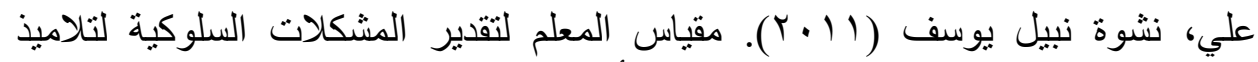

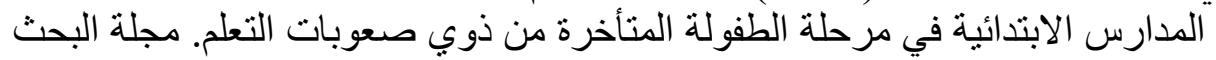

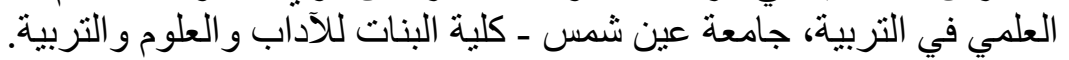

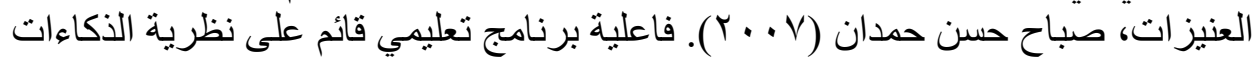

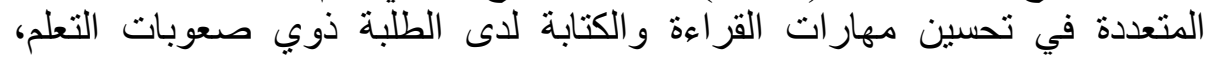

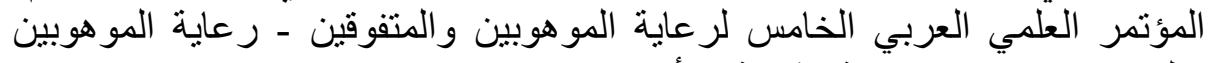

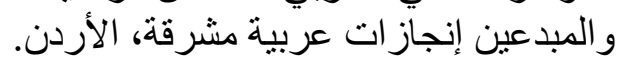

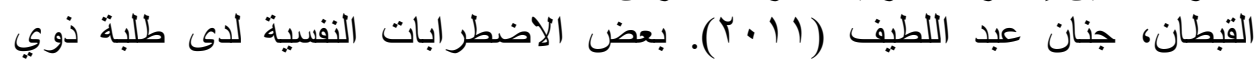
صعوبات التعليم في مدارس التعليم الأساسي بمحافظة مسقط. جامعة نزوى، كلية

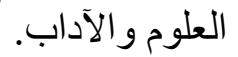

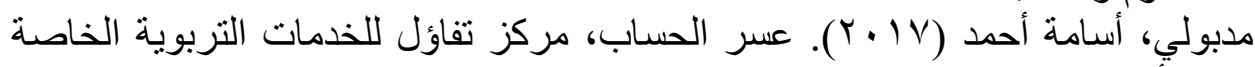

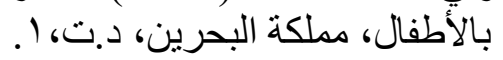

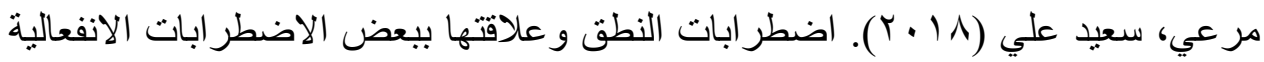

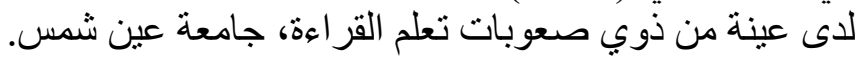

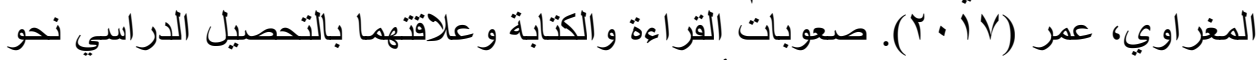

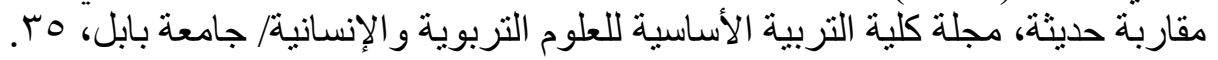

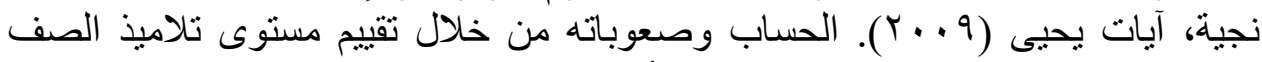

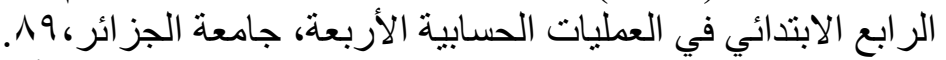

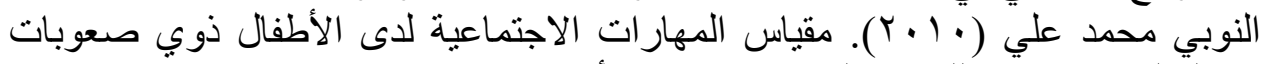

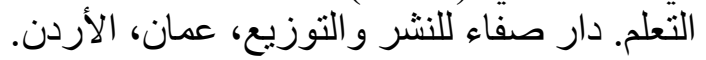

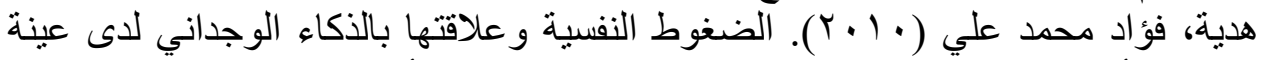
من الأطفال ذوب صعوبة القراءة في مرحلة الطفولة المتأخرة: دراسة وصفية الطية مقارنة،

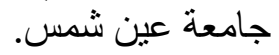


